NIST Special Publication 260-198

\title{
A Retuned Horwitz Procedure for Upgrading Certificates of Older Standard Reference Materials
}

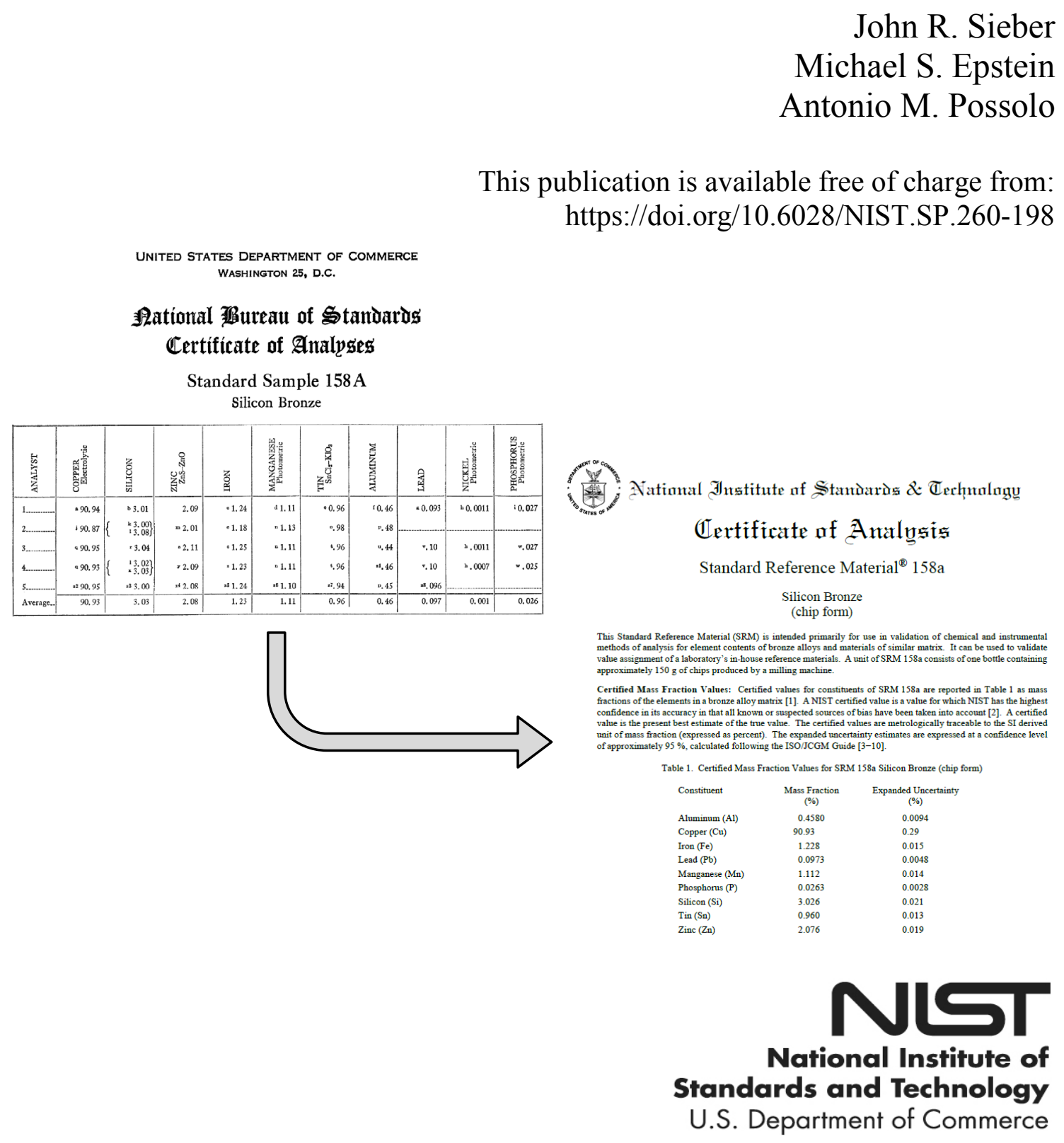


(This page intentionally blank) 
NIST Special Publication 260-198

\title{
A Retuned Horwitz Procedure for Upgrading Certificates of Older Standard Reference Materials
}

\author{
John R. Sieber \\ Michael S. Epstein \\ Chemical Sciences Division \\ Material Measurement Laboratory \\ Antonio M. Possolo \\ Statistical Engineering Division \\ Information Technology Laboratory
}

This publication is available free of charge from:

https://doi.org/10.6028/NIST.SP.260-198

May 2019

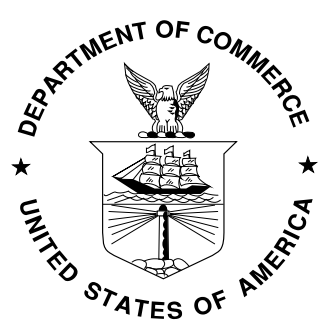

U.S. Department of Commerce Wilbur L. Ross, Jr., Secretary

National Institute of Standards and Technology Walter Copan, NIST Director and Undersecretary of Commerce for Standards and Technology 
Certain commercial entities, equipment, or materials may be identified in this document to describe an experimental procedure or concept adequately. Such identification is not intended to imply recommendation or endorsement by the National Institute of Standards and Technology, nor is it intended to imply that the entities, materials, or equipment are necessarily the best available for the purpose.

National Institute of Standards and Technology Special Publication 260-198 Natl. Inst. Stand. Technol. Spec. Publ. 260-198, 31 pages (May 2019) CODEN: NSPUE2

This publication is available free of charge from: https://doi.org/10.6028/NIST.SP.260-198 


\begin{abstract}
Many older certified reference materials have Certificates of Analysis that do not fully comply with ISO Guide 31, Reference Materials - Contents of Certificates, Labels, and Accompanying Documentation. This applies to many NIST Standard Reference Materials (SRM) that have published uncertainty estimates not compliant with the Guide to the Expression of Uncertainty in Measurement (GUM) or have no uncertainty estimates at all. When older certification records are sparse and insufficient data are available for a full, modern, statistical analysis, it can be useful to apply the concept of the Horwitz formula relating measurement uncertainty to constituent mass fraction across a population of results from a variety of test methods. Because the quality inherent in results obtained during SRM development projects is likely better than the quality of at least some data used by Horwitz to derive the published relationship, it is sensible to retune the concept, using a large set of results from NIST SRM projects. This approach is described with examples provided, and its utility is discussed in comparison to and in combination with alternative approaches such as Type A evaluation using Student's $t$ coverage intervals and a Bayesian procedure. A six-step process is defined to tackle a variety of situations encountered with older SRMs. NIST is applying this approach to upgrade numerous certificates for metals, ores and related materials.
\end{abstract}

\title{
Key words
}

Certificate of Analysis; ISO Guide 31; Reference materials; Uncertainty estimation. 


\section{Table of Contents}

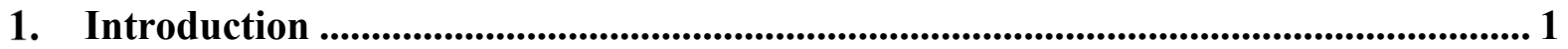

2. Archived Records ............................................................................................................. 1

3. Statistical Treatment .......................................................................................................... 2

4. Predicting Expanded Uncertainty...................................................................................... 2

4.1. Extreme Expanded Uncertainties .................................................................. 4

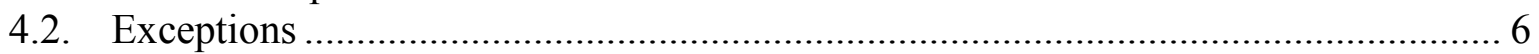

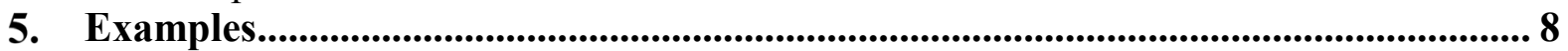

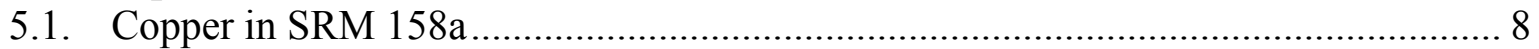

5.2. Application of Retuned Horwitz to Contemporary SRM 2161 ................................ 11

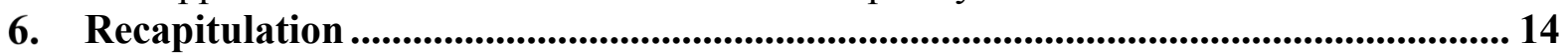

7. Conclusions...................................................................................................................... 15

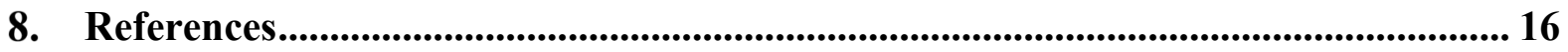

Appendix ......................................................................................................................................... 17

1961 Certificate for SRM 158a Silicon Bronze (chip form) ............................................. 17

2018 Certificate for SRM 158a Silicon Bronze (chip form) ……………......................... 18

Certificate for SRM 2161 Low Alloy Steel (chip form) ……………………………...... 22

\section{List of Tables}

Table 1. Details for measurands corresponding to red dots in Figure 2............................... 5

Table 2. Details for measurands corresponding to blue dots in Figure 2. ……....................... 5

Table 3. Details for measurands corresponding to red dots in Figure 3.................................. 6

Table 4. Details for measurands corresponding to green dots in Figure 3............................. 7

Table 5. Summary of certified values, $w_{\text {Cert }}$, and expanded uncertainties, $U_{95 \text { Cert }}$, for

SRM 2161 compared to $U_{95 P}$ from Type A evaluation ...................................................... 14

\section{List of Figures}

Figure 2. Expanded uncertainty $U_{\mathrm{S}}(w)$ derived from a Student's $t$ coverage interval plotted against the corresponding estimate $U_{\mathrm{H}}(w)$ derived from Horwitz's original formula............... 3 Figure 3. Relative expanded uncertainty predicted by retuned Horwitz's formula, $U_{\mathrm{HR}}(w) / w$ versus relative expanded uncertainty $U_{\mathrm{S}}(w) / w$ from a Student's $t$ coverage interval.............. 4 Figure 4. Expanded uncertainty $U_{\mathrm{S}}(w)$ from Type A evaluation, where it is practicable, plotted against expanded uncertainty $U_{\mathrm{H}}(w)$ produced by Horwitz's original formula. .......... 6 Figure 5. Excerpt from original 1961 certificate of analysis for SRM 158a Silicon Bronze showing the table of values. Superscript letters indicate test methods.................................. 9 Figure 6. For copper in SRM 158a, the lower, blue probability density corresponds to the lognormal prior distribution for expanded uncertainty with mean $=0.145 \%$ (blue dot)........ 9 Figure 7. Posterior probability density of $w_{\mathrm{Cu}}$ in SRM 158a........................................... 10 Figure 8. Table 1 reproduced from the 2018 version of the SRM 158a certificate of analysis.

Figure 9. Relation between "revised" expanded uncertainty $U_{95}\left(w_{\text {Rev }}\right)$ from the six-step imputation procedure, and expanded uncertainty estimates $U_{95}\left(w_{\text {Cert }}\right)$ from SRM $2161 \ldots . . . .13$ 


\section{Introduction}

From about 1955 to 1975 , some Standard Reference Materials (SRM) were issued with Certificates of Analysis that published all measured results for the constituents of interest. Most of these certificates are for alloys, and most show a summary value for each constituent in the form of an Average (or Grand Average) of the measured results or a Recommended Value like the average, but of unknown derivation. Rarely do these certificates include estimates of uncertainty accompanying the average or recommended value. When there are estimates of uncertainty, they are the standard deviation of the laboratory means, or they are of unknown derivation and often described as based on judgement. In this paper, the subject SRMs include alloys of steel, aluminum, tin, lead, copper, zinc, cast iron, iron ores, ferroalloys, and silica brick. In the SRM catalog, there were 48 SRMs with this type of certificate as of January 2015. Since that time, eight SRMs have been discontinued for lack of demand or because the supply has been depleted. However, the remaining such SRMs include a few that sell 10 units to 60 units per year, showing that some older SRMs remain relevant to modern chemical metrology. It may be that upgrading more certificates will improve the utility of other SRMs in this population, if defensible uncertainty estimates can be obtained.

For six such SRMs, the values have been revised, uncertainty estimates have been calculated, and new Certificates of Analysis have been prepared that comply with ISO Guide 31, Reference Materials - Contents of Certificates, Labels, and Accompanying Documentation requirements [1]. We believe the new estimates of uncertainty conform to the ISO Guide to the Expression of Uncertainty in Measurement (GUM) [2], and this paper presents the case that the Horwitz Retuned approach is both appropriate in the face of these requirements and reasonable in view of the applications to which SRM users apply these materials. By essentially giving these older SRMs new life, this approach preserves hundreds of thousands of dollars-worth of certified reference materials for the metals, mining, glass, and ceramics industries.

\section{Archived Records}

NIST collects and preserves records of SRM development projects in "R-folders," which is a name of unknown origin. Originally, the actual, paper folders were called Master Folders, but somewhere along the line that was changed. The records stored in R-folders include correspondence about the need for the project and the planning of material creation, analytes required to be measured, test methods, and expert laboratories that volunteered to perform analyses. Also included are records of processing performed at NIST or a collaborator for creation of the final SRM units, packaging for sale, label design, safety documents, storage of reserve quantities, funding, and pricing. Last, and perhaps most important, the R-folder contains test results and a record of the assignments of values. Many folders include draft(s) of the Certificates of Analysis.

Over the nearly 12 decades of SRM development, the concept of value assignment changed as metrologists expanded the amount of information believed necessary to communicate the identity of each measurand, the assigned value, its uncertainty, and the level of confidence with which NIST believes the value is known. Since the beginning, some materials included estimates of uncertainty. However, uncertainties were not provided in most of the certificates until 1975. As the use of uncertainty increased, its understanding became more sophisticated. 
Frequently, a certificate would include an uncertainty that was based on judgement after review of the agreement among laboratory mean results. The uncertainty provided is what is now called a standard uncertainty. Rarely did the standard uncertainty include a component based on the repeatability of results within individual labs, because the labs most often reported just their overall mean result per test method, without the individual, replicate results. That was not a rule, because one can find lists of individual results in some R-folders.

In the worst of cases, there is no extant R-folder. The only documentation is the Certificate of Analysis (COA) and any previous certificates that were superseded. For the 46 SRMs that are the subject of this paper, the COAs contain a table of results from the collaborating laboratories. Typically, the table contains the laboratory's mean value for each analyte and each test method. In a few cases when there is a small number of analytes, the individual measurement results are listed, which enables calculation of a repeatability standard deviation. The same situation exists with records in the R-folders, i.e., papers contain laboratory mean values, and rarely, some papers contain replicate results. The authors prepared a grand tabulation of all available values collected in a single spreadsheet.

\section{Statistical Treatment}

Replicated measured values for the mass fraction $w$ of each of 447 measurands in 46 SRMs were examined with a view toward producing credible uncertainty evaluations to qualify the values assigned to the SRMs. For 443 of these measurands it was possible to perform a Type A evaluation of measurement uncertainty as described in the GUM, and to calculate an expanded uncertainty $U_{\mathrm{S}}(w)$ (corresponding to $95 \%$ coverage) using a percentile of a suitable Student's $t$ probability distribution.

The corresponding 443 pairs $\left(w, U_{\mathrm{S}}(w)\right)$ were used to retune the empirical relationship, between $w$ and the associated uncertainty, that was originally determined by Horwitz [3], to improve its accuracy when it is applied to these SRMs. Given a value $w$ of the mass fraction, the retuned Horwitz's formula produces an estimate $U_{\mathrm{HR}}(w)$ of the corresponding expanded uncertainty. For the remaining four measurands (Table 3), $U_{\mathrm{S}}(w)$ could not be computed, either because a single measured value was obtained, or because the replicated measured values were identical. For these, only $U_{\mathrm{HR}}(w)$ is available. For 30 measurands, the difference between $U_{\mathrm{S}}(w)$ and $U_{\mathrm{HR}}(w)$ is appreciable, which casts doubt on the adequacy of both. And for some of the other $447-30=417$ measurands, it may well be that neither $U_{\mathrm{S}}(w)$ nor $U_{\mathrm{HR}}(w)$ will be credible, even when these two evaluations are in approximate agreement. For example, both may appear to be too high or too low, based on what is reasonable to expect given the analyte and the analytical methods. In all such cases, additional information will be required to arrive at a credible uncertainty evaluation.

When $U_{\mathrm{S}}(w)$ is much too small, and substantially smaller than $U_{\mathrm{HR}}(w)$, it is possible to employ a Bayesian procedure to pull the former up toward the latter. This procedure is illustrated for the mass fraction of copper in SRM 158a. However, only an expert can judge whether the result is fit for purpose, based on knowledge of the capabilities of the applied test methods.

\section{Predicting Expanded Uncertainty}

Suppose that $n$ replicated determinations were made of the mass fraction (expressed as a percentage) of a measurand, and that these determinations have average $w$ and standard 
deviation $s$. Horwitz's formula (whose graph is called the Horwitz curve) [3] provides a prediction for the corresponding standard uncertainty as $u_{\mathrm{H}}(w)=2(w / \sqrt{n})(w / 100)^{-0.15} / 100$, and $U_{\mathrm{H}}(w)=2 u_{\mathrm{H}}(w)$ is taken as the corresponding predicted expanded uncertainty (for approximately $95 \%$ coverage). If there are at least two replicates, and all replicates are not identical, then a Type A evaluation performed according to the GUM produces $U_{\mathrm{S}}(w)=t_{(n-1), 0.975} / \sqrt{n}$ as the expanded uncertainty (for approximately $95 \%$ coverage), where $t_{(n-1), 0.975}$ denotes the $97.5^{\text {th }}$ percentile of Student's $t$ distribution with $(n-1)$ degrees of freedom.

Horwitz's formula is based on a review of over 10000 interlaboratory results, published primarily in the Journal of AOAC International. It is remarkable that results of collaborative trials fit the curve regardless of the nature of the analyte and the test material, or the physical principle underlying the measurement process [4]. Even though the formula must not be used blindly $[4,5]$, it may give useful estimates of uncertainty. The accuracy of estimates is expected to improve if Horwitz's formula is retuned using the data in hand for 443 of the 447 measurands in the collection under examination. Figure 1 shows a straight line fitted to pairs of corresponding values of $U_{\mathrm{S}}(w)$ and $U_{\mathrm{H}}(w)$ using a Deming regression errors-in-variables procedure $[6,7]$. The thick (blue) line has equation $\log _{10} U_{\mathrm{S}}(w)=0.5625 \log _{10} U_{\mathrm{H}}(w)-1.052$, with slope and intercept estimated by Deming regression as implemented in function mcreg of $\mathrm{R}$ package $m c r[8,9]$. The thin (magenta) line has slope $=1$ and intercept $=0$.

According to the retuned relationship, the expanded uncertainty grows less rapidly with the value of the measurand than Horwitz's original formula predicts. Let $U_{\mathrm{HR}}(w)$ denote the value for the expanded uncertainty corresponding to the mass fraction $w$ of the measurand that is produced by the retuned Horwitz's formula.

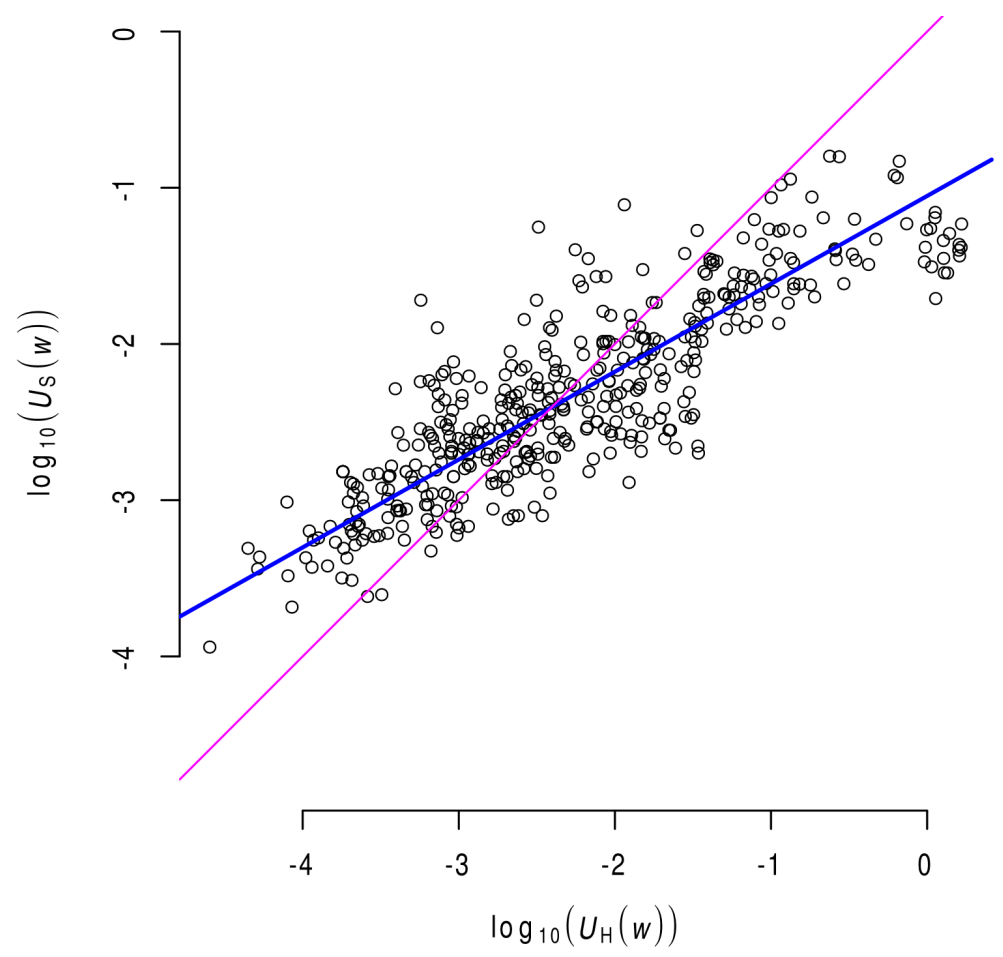

Figure 1. Expanded uncertainty $U_{\mathrm{S}}(w)$ derived from a Student's $t$ coverage interval plotted against the corresponding estimate $U_{\mathrm{H}}(w)$ derived from Horwitz's original formula. 


\subsection{Extreme Expanded Uncertainties}

The retuned Horwitz's formula occasionally produces predictions, $U_{\mathrm{HR}}(w)$, of expanded uncertainty that may be judged much too high or much too low when compared to $U_{\mathrm{s}}(w)$, both relative to the value of the measurand. Figure 2 highlights both, and Tables 1 and 2 list the corresponding measurands. The magenta line has slope $=1$ and intercept $=0$. Note the logarithmic scales on both axes. In Figure 2, red dots correspond to cases listed in Table 1, where predicted relative expanded uncertainty is considerably greater than what the data suggest. Blue dots correspond to cases in Table 2, where the relative expanded uncertainty predicted by the retuned Horwitz's formula is noticeably smaller than what a conventional Type A evaluation produces.

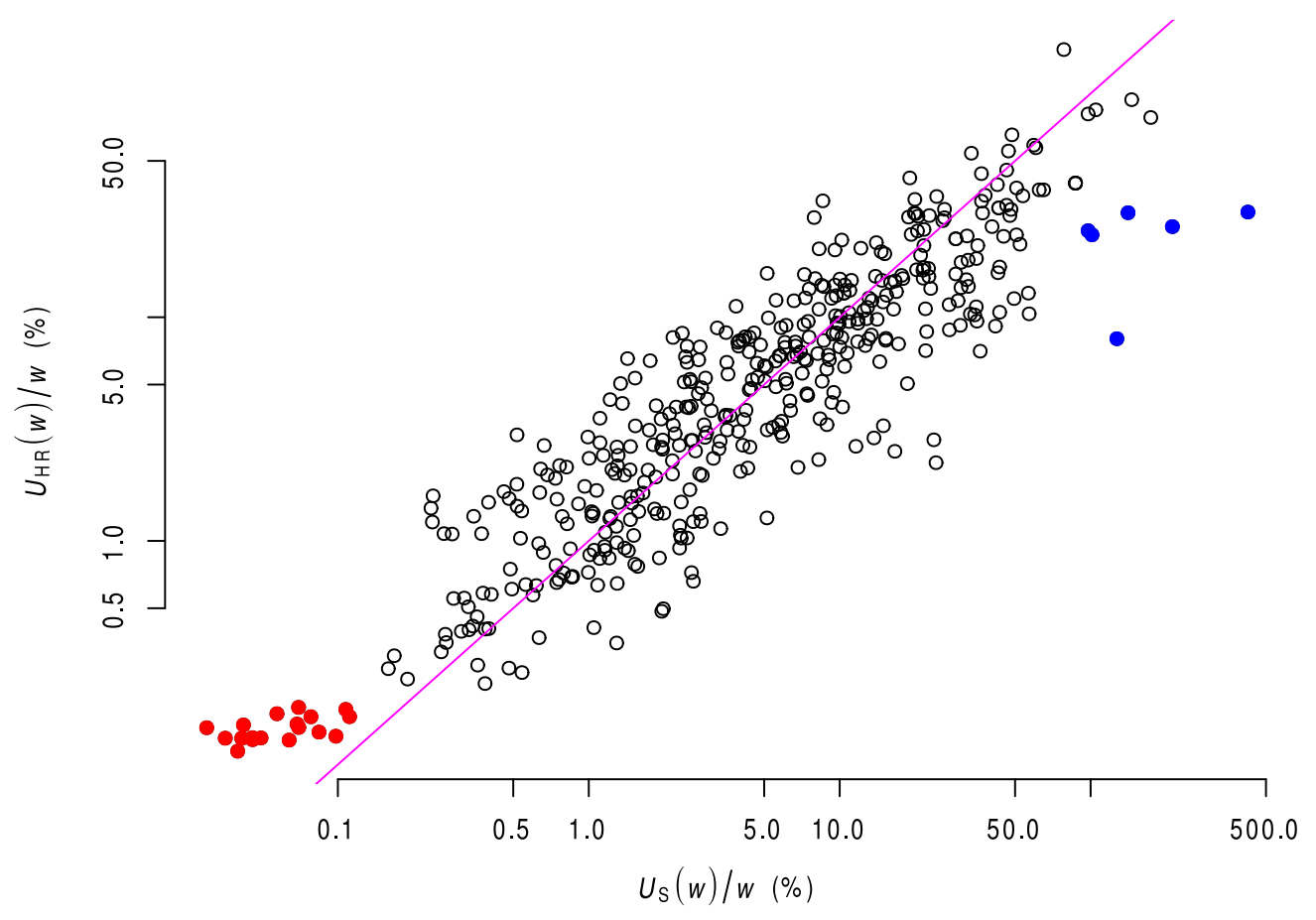

Figure 2. Relative expanded uncertainty predicted by retuned Horwitz's formula, $U_{\mathrm{HR}}(w) / w$ versus relative expanded uncertainty $U_{\mathrm{S}}(w) / w$ from a Student's $t$ coverage interval. 
Table 1. Details for measurands corresponding to red dots in Figure 2.

\begin{tabular}{|r|c|c|c|c|c|}
\hline SRM & Measurand & $n$ & $w$ & $U_{\mathrm{S}}(w)$ & $U_{\mathrm{HR}}(w)$ \\
\hline $54 \mathrm{~d}$ & $\mathrm{Sn}$ & 8 & 88.57 & 0.035 & 0.10 \\
\hline $59 \mathrm{a}$ & $\mathrm{Fe}$ & 5 & 50.05 & 0.054 & 0.09 \\
\hline $59 \mathrm{a}$ & $\mathrm{Si}$ & 5 & 48.10 & 0.034 & 0.09 \\
\hline $64 \mathrm{c}$ & $\mathrm{Cr}$ & 5 & 68.00 & 0.029 & 0.10 \\
\hline $68 \mathrm{c}$ & $\mathrm{Mn}$ & 6 & 80.04 & 0.028 & 0.11 \\
\hline 89 & $\mathrm{SiO}_{2}$ & 7 & 65.33 & 0.055 & 0.09 \\
\hline $158 \mathrm{a}$ & $\mathrm{Cu}$ & 5 & 90.93 & 0.042 & 0.12 \\
\hline 196 & $\mathrm{Cr}$ & 7 & 70.81 & 0.070 & 0.09 \\
\hline 690 & $\mathrm{Fe}$ & 5 & 66.86 & 0.046 & 0.10 \\
\hline 692 & $\mathrm{Fe}$ & 7 & 59.58 & 0.042 & 0.09 \\
\hline 693 & $\mathrm{Fe}$ & 6 & 65.11 & 0.020 & 0.10 \\
\hline 871 & $\mathrm{Cu}$ & 5 & 91.70 & 0.059 & 0.12 \\
\hline 872 & $\mathrm{Cu}$ & 5 & 87.35 & 0.040 & 0.12 \\
\hline 874 & $\mathrm{Cu}$ & 5 & 88.49 & 0.037 & 0.12 \\
\hline 875 & $\mathrm{Cu}$ & 5 & 87.85 & 0.043 & 0.12 \\
\hline 879 & $\mathrm{Cu}$ & 5 & 57.75 & 0.064 & 0.09 \\
\hline 880 & $\mathrm{Cu}$ & 5 & 54.52 & 0.031 & 0.09 \\
\hline 882 & $\mathrm{Ni}$ & 4 & 65.25 & 0.051 & 0.11 \\
\hline
\end{tabular}

The certificates of SRMs 64c, 68c, 690, and higher numbers, include uncertainty evaluations for the measurands that appear in them and that are listed in this table.

Table 2. Details for measurands corresponding to blue dots in Figure 2.

\begin{tabular}{|c|c|c|c|c|c|}
\hline $\mathrm{SRM}$ & Measurand & $n$ & $w$ & $U_{\mathrm{S}}(w)$ & $U_{\mathrm{HR}}(w)$ \\
\hline 89 & $\mathrm{As}_{2} \mathrm{O}_{3}$ & 3 & 0.0440 & 0.0560 & 0.0035 \\
\hline 89 & $\mathrm{ZrO}_{2}$ & 2 & 0.0045 & 0.0191 & 0.0013 \\
\hline $342 \mathrm{a}$ & $\mathrm{Mo}$ & 3 & 0.0057 & 0.0057 & 0.0013 \\
\hline 690 & $\mathrm{~S}$ & 3 & 0.0037 & 0.0052 & 0.0011 \\
\hline 882 & $\mathrm{C}$ & 2 & 0.0065 & 0.0064 & 0.0016 \\
\hline 882 & $\mathrm{Si}$ & 2 & 0.0060 & 0.0127 & 0.0015 \\
\hline
\end{tabular}




\subsection{Exceptions}

Figure 3 shows the 34 cases that require a customized uncertainty evaluation. For four of these, a conventional Type A evaluation cannot be performed either because there is only one determination of the value of the measurand, or because the standard deviation of the replicated determinations is 0 . For these four, only the values predicted by the retuned Horwitz's formula are available (marked by red dots in the figure and listed in Table 3). For the other 30 (marked by green dots and listed in Table 4$)$, the predicted relative expanded uncertainty $U_{\mathrm{S}}(w) / w$ corresponding to a Student's $t$ coverage interval is less than $0.3 \%$, which may be too low to be credible. The (blue) line with slope $=0.5625$ and intercept $=-1.052$ corresponds to the retuned Horwitz's formula.

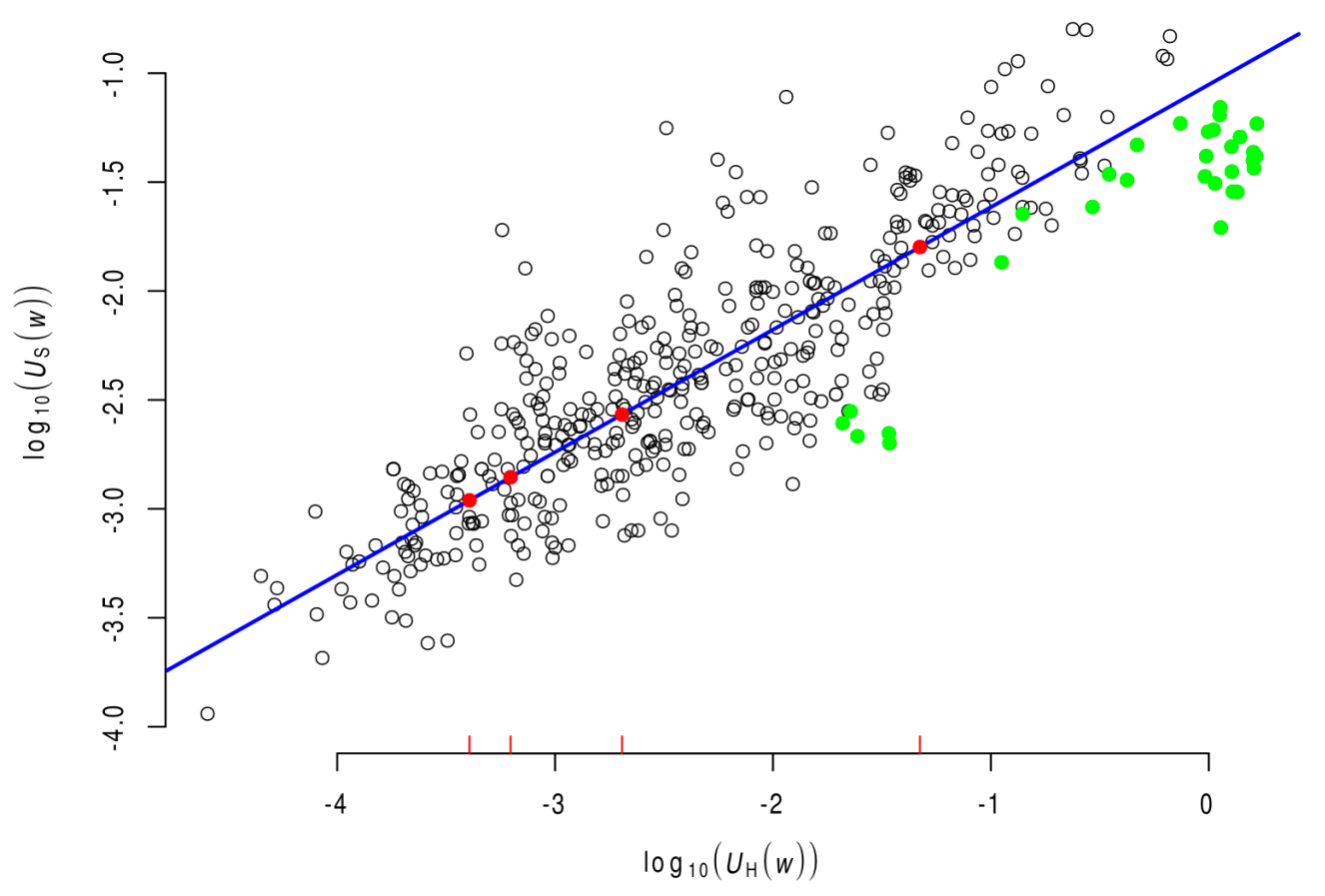

Figure 3. Expanded uncertainty $U_{\mathrm{S}}(w)$ from Type A evaluation, where it is practicable, plotted against expanded uncertainty $U_{\mathrm{H}}(w)$ produced by Horwitz's original formula.

Table 3. Details for measurands corresponding to red dots in Figure 3.

\begin{tabular}{|c|c|c|c|c|}
\hline SRM & Measurand & $n$ & $w$ & $U_{\mathrm{HR}}(w)$ \\
\hline $33 \mathrm{e}$ & $\mathrm{P}$ & 2 & 0.0050 & 0.0014 \\
\hline $82 \mathrm{~b}$ & $\mathrm{Ni}$ & 4 & 1.220 & 0.016 \\
\hline 196 & $\mathrm{~S}$ & 2 & 0.0030 & 0.0011 \\
\hline $342 \mathrm{a}$ & $\mathrm{Ti}$ & 2 & 0.0200 & 0.0027 \\
\hline
\end{tabular}


Table 4. Details for measurands corresponding to green dots in Figure 3.

\begin{tabular}{|c|c|c|c|l|l|l|l|c|}
\hline SRM & Measurand & $n$ & $w$ & $U_{\mathrm{S}}(w)$ & $\% U_{\mathrm{S}}(w) / w$ & $U_{\mathrm{HR}}(w)$ & $\% U_{\mathrm{HR}}(w) / w$ & $\underline{\underline{\underline{\mathrm{S}}}}(w)$ \\
\hline $30 \mathrm{f}$ & $\mathrm{Cr}$ & 5 & 0.94 & 0.0022 & 0.23 & 0.013 & 1.4 & 0.17 \\
\hline $54 \mathrm{~d}$ & $\mathrm{Sn}$ & 8 & 88.57 & 0.035 & 0.040 & 0.10 & 0.11 & 0.34 \\
\hline $59 \mathrm{a}$ & $\mathrm{Fe}$ & 5 & 50.05 & 0.054 & 0.11 & 0.088 & 0.18 & 0.61 \\
\hline $59 \mathrm{a}$ & $\mathrm{Si}$ & 5 & 48.10 & 0.034 & 0.070 & 0.087 & 0.18 & 0.39 \\
\hline $64 \mathrm{c}$ & $\mathrm{C}$ & 7 & 4.68 & 0.014 & 0.29 & 0.026 & 0.55 & 0.54 \\
\hline $64 \mathrm{c}$ & $\mathrm{Cr}$ & 5 & 68.00 & 0.029 & 0.042 & 0.10 & 0.15 & 0.28 \\
\hline $68 \mathrm{c}$ & $\mathrm{Mn}$ & 6 & 80.04 & 0.029 & 0.036 & 0.11 & 0.13 & 0.28 \\
\hline $73 \mathrm{c}$ & $\mathrm{Cr}$ & 4 & 12.82 & 0.034 & 0.27 & 0.049 & 0.38 & 0.69 \\
\hline 89 & $\mathrm{SiO}$ & 7 & 65.33 & 0.055 & 0.084 & 0.091 & 0.14 & 0.60 \\
\hline $115 \mathrm{a}$ & $\mathrm{Ni}$ & 7 & 14.49 & 0.024 & 0.17 & 0.045 & 0.31 & 0.54 \\
\hline $134 \mathrm{a}$ & $\mathrm{Mo}$ & 12 & 8.35 & 0.023 & 0.27 & 0.029 & 0.35 & 0.78 \\
\hline 155 & $\mathrm{C}$ & 9 & 0.91 & 0.0022 & 0.24 & 0.011 & 1.2 & 0.20 \\
\hline $158 \mathrm{a}$ & $\mathrm{Cu}$ & 5 & 90.93 & 0.042 & 0.046 & 0.186 & 0.13 & 0.36 \\
\hline 163 & $\mathrm{C}$ & 13 & 0.93 & 0.0025 & 0.27 & 0.010 & 1.1 & 0.25 \\
\hline 163 & $\mathrm{Cr}$ & 12 & 0.98 & 0.0028 & 0.29 & 0.011 & 1.1 & 0.26 \\
\hline 196 & $\mathrm{Cr}$ & 7 & 70.83 & 0.070 & 0.098 & 0.095 & 0.13 & 0.74 \\
\hline 341 & $\mathrm{Ni}$ & 6 & 20.32 & 0.032 & 0.16 & 0.055 & 0.27 & 0.59 \\
\hline 690 & $\mathrm{Fe}$ & 5 & 66.86 & 0.046 & 0.069 & 0.102 & 0.15 & 0.45 \\
\hline 692 & $\mathrm{Fe}$ & 7 & 59.58 & 0.042 & 0.070 & 0.087 & 0.15 & 0.48 \\
\hline 693 & $\mathrm{Fe}$ & 6 & 65.11 & 0.020 & 0.030 & 0.095 & 0.15 & 0.21 \\
\hline 871 & $\mathrm{Cu}$ & 5 & 91.70 & 0.059 & 0.064 & 0.12 & 0.13 & 0.50 \\
\hline 872 & $\mathrm{Cu}$ & 5 & 87.35 & 0.040 & 0.046 & 0.12 & 0.13 & 0.35 \\
\hline 874 & $\mathrm{Cu}$ & 5 & 88.49 & 0.037 & 0.041 & 0.12 & 0.13 & 0.32 \\
\hline 875 & $\mathrm{Cu}$ & 5 & 87.85 & 0.043 & 0.049 & 0.12 & 0.13 & 0.37 \\
\hline 879 & $\mathrm{Cu}$ & 5 & 57.75 & 0.064 & 0.11 & 0.095 & 0.16 & 0.68 \\
\hline 880 & $\mathrm{Cu}$ & 5 & 54.52 & 0.031 & 0.057 & 0.092 & 0.17 & 0.34 \\
\hline 880 & $\mathrm{Ni}$ & 4 & 18.14 & 0.047 & 0.26 & 0.058 & 0.32 & 0.86 \\
\hline 882 & $\mathrm{Cu}$ & 4 & 31.04 & 0.059 & 0.19 & 0.075 & 0.24 & 0.79 \\
\hline 882 & $\mathrm{Ni}$ & 4 & 65.25 & 0.051 & 0.078 & 0.11 & 0.16 & 0.48 \\
\hline 1157 & $\mathrm{C}$ & 4 & 0.84 & 0.0020 & 0.24 & 0.013 & 1.6 & 0.15 \\
\hline
\end{tabular}




\section{Examples}

\subsection{Copper in SRM 158a}

This example serves to illustrate how a Type A uncertainty evaluation that may appear unrealistically low may be "pulled up" with the help of the retuned Horwitz's formula, in those cases where this formula predicts a value for the uncertainty that is greater than that produced by evaluation based on the data alone. However, two caveats should be noted. First, in general and in this example, the increase in the value of the expanded uncertainty is modest and may still be insufficient to make it credible. Second, this may not be, and likely will not be, the best way to produce credible uncertainty evaluations in general.

Two alternatives that may be much better involve: (i) relying on expert opinion about the performance of the analytical methods at the time when the material was measured; (ii) incorporating information from uncertainty evaluations for similar reference materials that were produced at about the same time as the material under review using comparable analytical methods. The same (Bayesian) procedure illustrated below would continue to offer a suitable mechanism to bring to bear the relevant information derived from (i) or from (ii), just the same as it brings to bear the prediction made using the retuned Horwitz's formula. This example demonstrates how this procedure works.

The 1961 certificate for SRM 158a Silicon Bronze, reproduced in part as Fig. 4, lists results for five determinations of the mass fraction of copper, determined using electrolysis methods with different digestion acids: $90.94 \%, 90.87 \%, 90.95 \%, 90.93 \%$, and $90.95 \%$. In Figure 4, superscript letters indicate test methods listed in the certificate. The certificate gives the average of these determinations, $90.93 \%$, but does not qualify it with a statement of uncertainty. Since $U_{\mathrm{S}}\left(w_{\mathrm{Cu}}\right)=0.04 \%$, with corresponding relative uncertainty $0.046 \%$, may be deemed to be too optimistic, the goal of this section is to illustrate how the prediction for the expanded uncertainty derived from the retuned Horwitz's formula may be blended with those five determinations to produce an evaluation for the expanded uncertainty that may be more credible than the value derived from the experimental data alone.

The procedure that will accomplish this is a Bayesian procedure, where the expanded uncertainty predicted by the retuned Horwitz's formula is used as prior information. This information is called "prior" because it is assumed to be in hand before the five determinations above are used. This prior information includes an estimate of the expanded uncertainty; plus, it includes recognition of the considerable scatter of the points around the thick, blue line in Fig. 1. Both these facts may be encapsulated in a log-normal distribution for $U\left(w_{\mathrm{Cu}}\right)$, such that the expected value of $\log _{10} U\left(w_{\mathrm{Cu}}\right)$ is $0.5625 \log _{10} U_{\mathrm{H}}\left(w_{\mathrm{Cu}}\right)-1.052$, and the standard deviation is set equal to the standard deviation of the residuals from the Deming regression. The corresponding probability density is depicted as a (fairly) flat, blue curve in Figure 5. Also in Figure 5, the green dot marks the Type A evaluation of expanded uncertainty done according to the GUM with $U_{\mathrm{S}}\left(w_{\mathrm{Cu}}\right)=0.042 \%$. The taller, red curve is the probability density of the posterior distribution of expanded uncertainty with mean $=0.054 \%$ (open (red) circle). The red diamond is the expanded uncertainty derived from the posterior distribution of $w_{\mathrm{Cu}}$ with $U_{\mathrm{B}}\left(w_{\mathrm{Cu}}\right)=0.061 \%$, as explained for Figure 6. 


\section{Standard Sample 158 A \\ Silicon Bronze}

\begin{tabular}{|c|c|c|c|c|c|c|c|c|c|c|}
\hline 宏 & 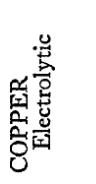 & 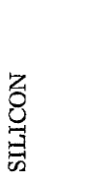 & 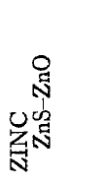 & Z & 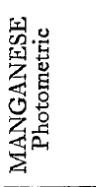 & Z্ট్ & 岕 & 岳 & 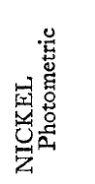 & 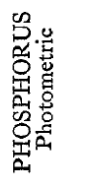 \\
\hline $1 \ldots$ & a 90.94 & b 3.01 & 2.09 & c 1.24 & d 1.11 & $\circ 0.96$ & f 0.46 & в 0.093 & h 0.0011 & i 0.027 \\
\hline 2......... & j 90.87 & $\left.\begin{array}{l}k 3,00 \\
13,08\end{array}\right\}$ & m 2.01 & - 1.18 & n 1.13 & 0.98 & p. 48 & & & \\
\hline 3 & c 90.95 & × 3.04 & 3. 2.11 & c 1.25 & n 1.11 & t. 96 & u. 44 & จ. 10 & h. 0011 & w. 027 \\
\hline 4 & व 90.93 & $\left.\begin{array}{r}13.02 \\
\times 3.03\end{array}\right\}$ & × 2.09 & $=1.23$ & ${ }^{n} 1.11$ & t. 96 & ะ1. 46 & จ. 10 & h. .0007 & w. 025 \\
\hline 5 & z2 90.95 & z3 3.00 & $z^{4} 2.08$ & ${ }^{25} 1.24$ & ${ }^{26} 1.10$ & ${ }^{2 \pi} .94$ & D. 45 & ${ }^{88} .096$ & & \\
\hline Average_- & 90.93 & 3.03 & 2.08 & 1.23 & 1.11 & 0.96 & 0.46 & 0.097 & 0.001 & 0.026 \\
\hline
\end{tabular}

Figure 4. Excerpt from original 1961 certificate of analysis for SRM 158a Silicon

Bronze showing the table of values. Superscript letters indicate test methods.

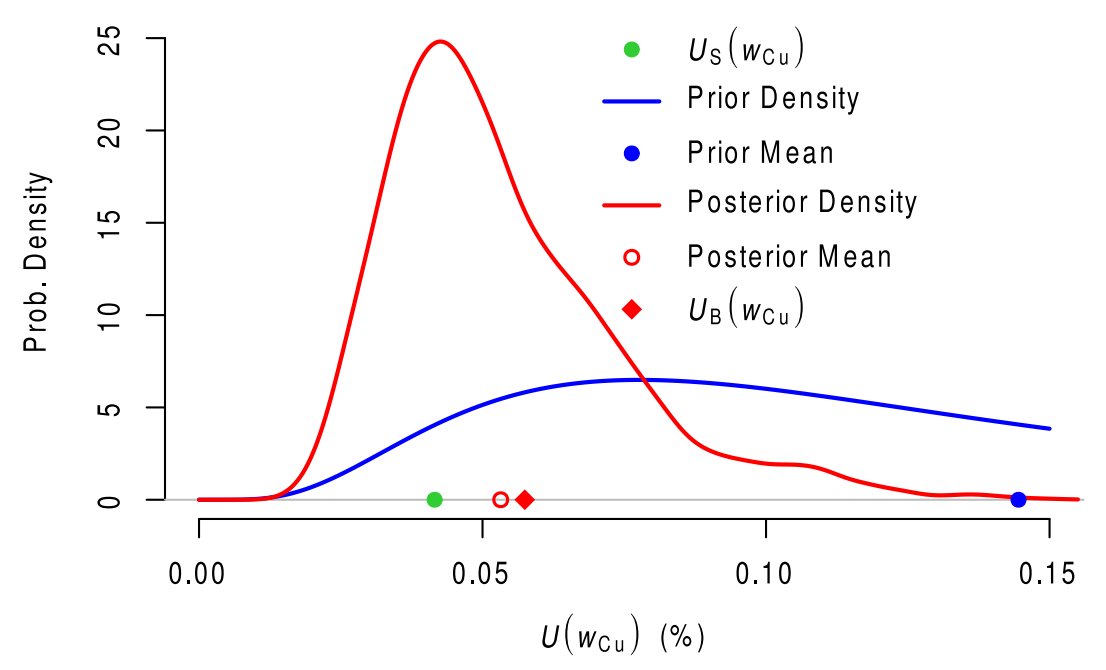

Figure 5. For copper in SRM 158a, the lower, blue probability density corresponds to the lognormal prior distribution for expanded uncertainty with mean $=0.145 \%$ (blue dot).

The other unknown is the mass fraction of copper in the material, $w_{\mathrm{Cu}}$. For the Bayesian machinery to operate, this mass fraction also must be assigned a prior distribution. A uniform distribution concentrated on the mass fraction interval $(0.5,1)$ captures the fact that the mass fraction of copper in common varieties of bronze is $>50 \%$. However, a uniform prior 
distribution on $(0,1)$ leads essentially to the same results. A sample was drawn from the joint posterior distribution of $w_{\mathrm{Cu}}$ and of $U\left(w_{\mathrm{Cu}}\right)$, and the corresponding (marginal) probability densities are depicted, one in Fig. 5, the other in Fig. 6. In Figure 6, the shaded, pink area amounts to $95 \%$ of the area under the curve. Its footprint on the horizontal axis, indicated by a thick, red line segment, is a $95 \%$ coverage interval for the true value of the mass fraction of $\mathrm{Cu}$ in the material. One half the length of the line segment is $U_{\mathrm{B}}\left(w_{\mathrm{Cu}}\right)=0.061 \%$, shown in the legend of Fig. 5. The two estimates of uncertainty are in fair agreement, as should be expected: the mean of the posterior distribution uncertainty in $w_{\mathrm{Cu}}$ is $U\left(w_{\mathrm{Cu}}\right)=0.054 \%$, and the $95 \%$ coverage interval for the true value of $w_{\mathrm{cu}}$, derived from the corresponding posterior distribution (Fig. 6), is $U_{\mathrm{B}}\left(w_{\mathrm{Cu}}\right)=0.061 \%$. In summary, application of a Bayesian updating procedure, implemented using facilities of $\mathrm{R}$ package $m c m c[8,10]$, blends the information in the data with the prediction made by the retuned Horwitz's formula. In this case, it increases the relative expanded uncertainty only modestly and possibly insufficiently from $0.042 \%$ to $0.061 \%$.

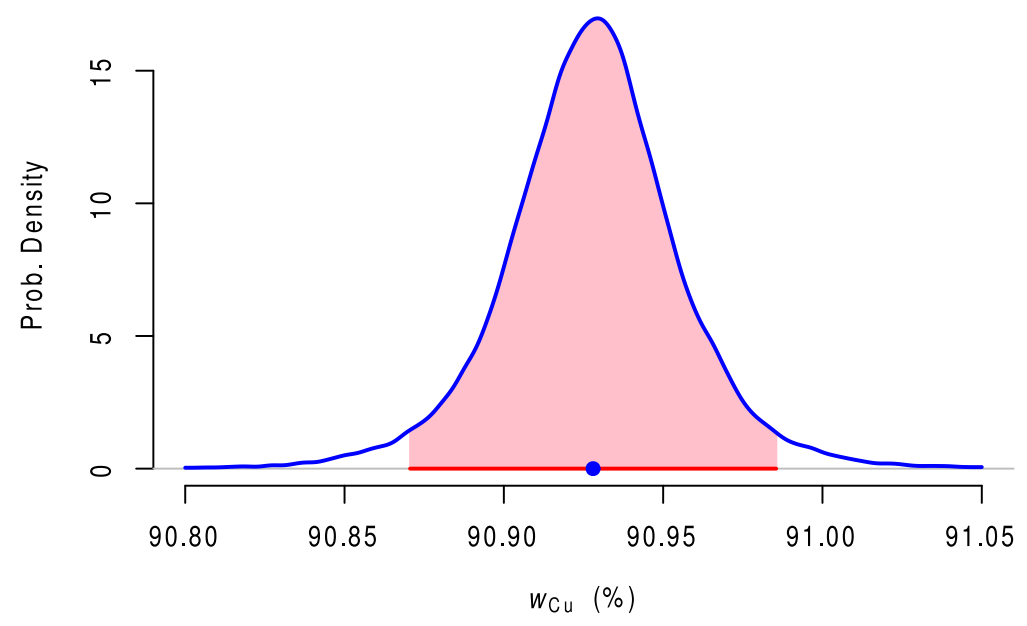

Figure 6. Posterior probability density of $w_{\mathrm{Cu}}$ in SRM $158 \mathrm{a}$.

For the creation of a revised certificate of analysis for SRM 158a, the expanded uncertainty for the certified copper value was assigned as $U\left(w_{\mathrm{Cu}}\right)=0.29 \%$. This estimate is based on expert judgement that a relative uncertainty of $0.3 \%$ is about the best that can be expected from a valid test method. The classical test method used to determine copper is a good example of a proven method having relative uncertainty substantially $<1 \%$. The authors have the benefit of records from an expert analyst, who performed numerous determinations of copper in brass and other copper alloys [11].

The revised values in Table 1 of the 2018 certificate for SRM 158a Silicon Bronze are displayed in Fig. 7. Comparing to Figure 4, the element nickel is missing from the revised table. In the revised Certificate of Analysis, nickel is given as an information value, because it was determined using just a single method with poor agreement among analysts. 
Table 1. Certified Mass Fraction Values for SRM 158a Silicon Bronze (chip form)

Constituent

Aluminum (A1)

Copper $(\mathrm{Cu})$

Iron $(\mathrm{Fe})$

Lead $(\mathrm{Pb})$

Manganese (Mn)

Phosphorus (P)

Silicon ( $\mathrm{Si})$

Tin $(\mathrm{Sn})$

Zinc $(\mathrm{Zn})$
Mass Fraction

(\%)

0.4580

90.93

1.228

0.0973

1.112

0.0263

3.026

0.960

2.076
Expanded Uncertainty

0.0094

0.29

0.015

0.0048

0.014

0.0028

0.021

0.013

0.019

Figure 7. Table 1 reproduced from the 2018 version of the SRM 158a certificate of analysis.

\subsection{Application of Retuned Horwitz to Contemporary SRM 2161}

NIST SRM 2161 comprises chips of a low alloy steel. It is intended primarily for evaluating methods of analysis for several elements in such steels and materials with a similar matrix, or to validate value assignment of in-house reference materials. Published in March 2018, the certificate lists certified mass fraction values for 19 elements, and the associated expanded uncertainties for approximate coverage of the corresponding true values with $95 \%$ probability. The certified values and associated uncertainties were derived from a large collection of replicated determinations made using six different methods of analysis at NIST and at two collaborating laboratories, amounting to 3112 determinations in all (for those 19 elements). This data provided three or more independent test methods for most elements.

Consider cobalt, for example. There were 144 determinations made at NIST using X-ray fluorescence (XRF), and three additional groups of 8 determinations each, made at other laboratories, using arc spark optical emission spectrometry (ASOES) and inductively coupled plasma optical emission spectrometry (ICPOES). The certified value $(0.0256 \%)$ and the associated expanded uncertainty $(0.0036 \%)$ were determined by combining all individual determinations, considering their dispersion in each of the four groups, using an appropriate statistical model and method of data reduction.

For this illustration, suppose that the only information available comprises the averages of the four groups of determinations: $0.02113 \%, 0.02326 \%, 0.02541 \%$, and $0.03240 \%$. Many old certificates report results in this manner, and even the corresponding archives may contain no additional information. It so happens the average of these four averages, $0.0256 \%$, equals the certified value; however, and in general, such felicitous coincidence may not occur.

The procedure to impute uncertainty associated with such average uses just these averages and the retuned Horwitz relation, and involves these six steps: 
1) Compute the average $a=0.0256 \%$ of the $n=4$ reported estimates of the measurand, and its associated standard uncertainty $u(a)=0.0025 \%$, via a Type A evaluation (sample standard deviation of those estimates divided by the square root of $n$ );

2) Compute the endpoints of a $95 \%$ confidence interval for the true mean as $(a-k u(a)$, $a+k u(a))=(0.0178 \%, 0.0333 \%)$, where $k=3.182$ is the $97.5^{\text {th }}$ percentile of the Student's $t$ distribution with $(n-1)=3$ degrees of freedom;

3) Compute a provisional value for the expanded uncertainty as one half the length of the interval in (2): $U_{95 \mathrm{P}}=(0.0333 \%-0.0178 \%) / 2=0.0078 \%$;

4) Compute $\sigma_{\mathrm{H}}=2(a / 100)^{-0.15} / 100=0.0692 \%$ (noting that $a$ must be expressed as a percentage, a number between 0 and 100, which in this case it already is because its units are \%), and then obtain the Horwitz evaluation of the expanded uncertainty, $U_{95 \mathrm{H}}=2\left(a \sigma_{\mathrm{H}} n^{-0.5}\right)=0.00177 \%$;

5) Produce the evaluation of the expanded uncertainty corresponding to the retuned Horwitz relation: $U_{95 \mathrm{HR}}=10 \exp \left\{I_{\mathrm{D}}+S_{\mathrm{D}} \log _{10}\left(U_{95 \mathrm{H}}\right)\right\}=0.0025 \%$, where $I_{\mathrm{D}}=$ 1.0523 and $S_{\mathrm{D}}=0.5625$ denote the intercept and slope of the blue line in Fig. 1 fit to the data used to retune the original Horwitz relationship via Deming regression.

6) Define $U_{95}$ as the maximum of $U_{95 \mathrm{P}}, U_{95 \mathrm{HR}}$ and $0.003 \mathrm{a}$. If the maximum is the latter ( $0.3 \%$ of the average $a$ of the individual mean values), then the resulting $U_{95}$ should be validated by a subject matter expert.

Applying this procedure to the data for all elements having mass fractions listed in Table 1 of the certificate of SRM 2161 produces the results depicted in Fig. 8 (note the units \% and cg/g are equivalent) and listed in Table 5 in comparison to the certificate values, evaluated using all underlying data. In Figure 8, the red line indicates $U_{95}\left(w_{\text {Rev }}\right)=U_{95}\left(w_{\text {Cert }}\right)$. In this example, $U_{95}\left(w_{\text {Rev }}\right)=U_{95 \mathrm{HR}} \geq U_{95}\left(w_{\text {Cert }}\right)$, suggesting the imputation procedure may be more conservative than the most accurate uncertainty evaluation. For other SRMs, the values of $n$ and $k$ may be different. 


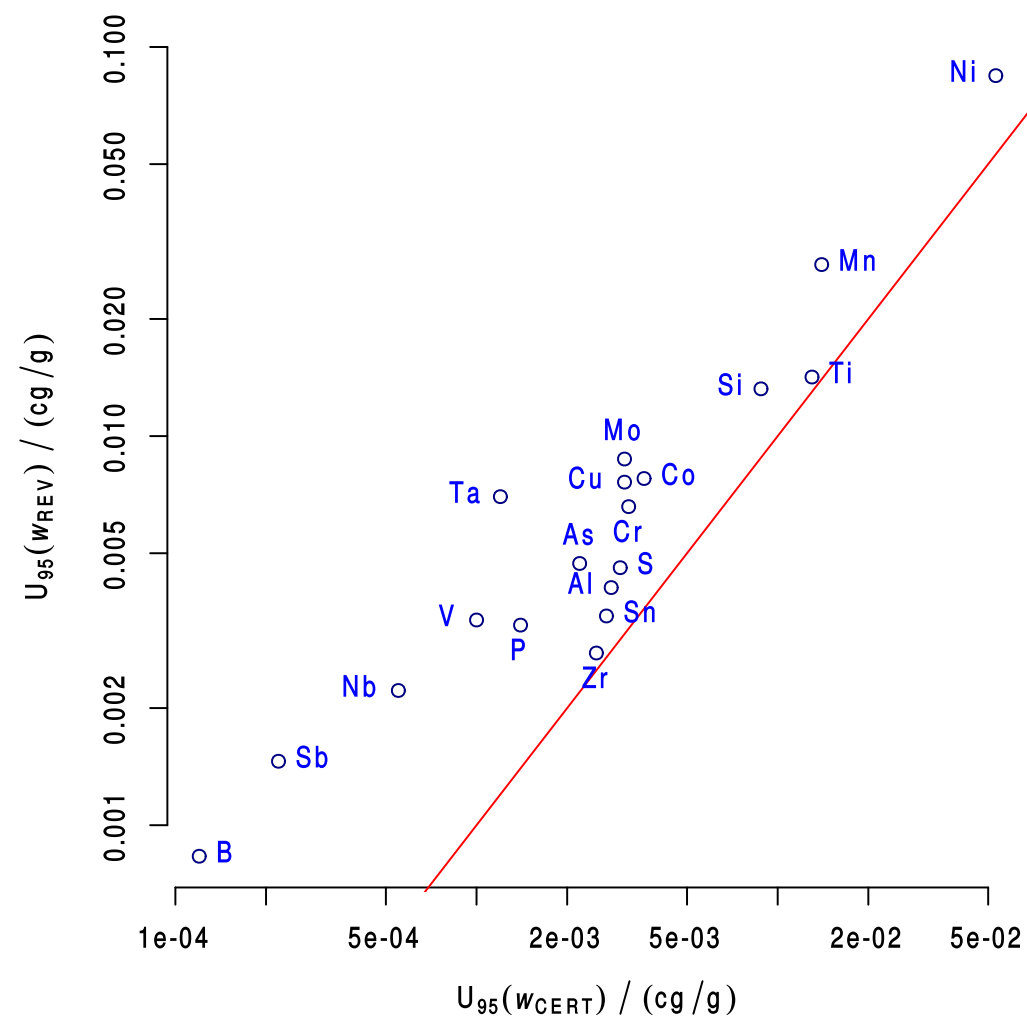

Figure 8. Relation between "revised" expanded uncertainty $U_{95}\left(w_{\text {Rev }}\right)$ from the six-step imputation procedure, and expanded uncertainty estimates $U_{95}\left(w_{\text {Cert }}\right)$ from SRM 2161. 
Table 5. Summary of certified values, $w_{\text {Cert }}$, and expanded uncertainties, $U_{95 \text { Cert }}$, for SRM 2161 compared to $U_{95}$ from Type A evaluation and $U_{95 \mathrm{HR}}$ from retuned Horwitz approach.

\begin{tabular}{|l|l|l|l|l|l|l|}
\hline \multicolumn{1}{|c|}{ Measurand } & \multicolumn{1}{c|}{$w_{\text {Cert }}$} & \multicolumn{1}{c|}{$U_{95 \mathrm{Cert}}$} & \multicolumn{1}{c|}{$U_{95 \mathrm{P}}$} & \multicolumn{1}{c|}{$U_{95 \mathrm{HR}}$} & \multicolumn{1}{c|}{$U_{95}$} & $N$ \\
\hline Aluminum (Al) & 0.0539 & 0.0028 & 0.0041 & 0.0034 & 0.0041 & 5 \\
\hline Antimony (Sb) & 0.00548 & 0.00022 & 0.0014 & 0.0015 & 0.0015 & 2 \\
\hline Arsenic (As) & 0.0131 & 0.0022 & 0.0047 & 0.0020 & 0.0047 & 3 \\
\hline Boron (B) & 0.00215 & 0.00012 & 0.00031 & 0.00083 & 0.00083 & 3 \\
\hline Cobalt (Co) & 0.0256 & 0.0036 & 0.0078 & 0.0025 & 0.0078 & 4 \\
\hline Chromium (Cr) & 0.2195 & 0.0032 & 0.0035 & 0.0066 & 0.0066 & 5 \\
\hline Copper (Cu) & 0.2973 & 0.0031 & 0.0074 & 0.0076 & 0.0076 & 5 \\
\hline Manganese (Mn) & 0.680 & 0.014 & 0.028 & 0.012 & 0.028 & 4 \\
\hline Molybdenum (Mo) & 0.1030 & 0.0031 & 0.0087 & 0.0053 & 0.0087 & 3 \\
\hline Niobium (Nb) & 0.01978 & 0.00055 & 0.00061 & 0.0022 & 0.0022 & 4 \\
\hline Nickel (Ni) & 1.999 & 0.053 & 0.084 & 0.022 & 0.084 & 3 \\
\hline Phosphorus (P) & 0.0407 & 0.0014 & 0.0033 & 0.0029 & 0.0033 & 5 \\
\hline Silicon (Si) & 0.1816 & 0.0088 & 0.013 & 0.0060 & 0.013 & 5 \\
\hline Sulfur (S) & 0.0347 & 0.0030 & 0.0046 & 0.0027 & 0.0046 & 5 \\
\hline Tin (Sn) & 0.0474 & 0.0027 & 0.0034 & 0.0032 & 0.0034 & 5 \\
\hline Tantalum (Ta) & 0.0522 & 0.0012 & 0.0070 & 0.0043 & 0.0070 & 2 \\
\hline Titanium (Ti) & 0.180 & 0.013 & 0.014 & 0.0064 & 0.014 & 4 \\
\hline Vanadium (V) & 0.0540 & 0.0010 & 0.0012 & 0.0034 & 0.0034 & 5 \\
\hline Zirconium (Zr) & 0.0132 & 0.0025 & 0.0028 & 0.0018 & 0.0028 & 4 \\
\hline
\end{tabular}

\section{Recapitulation}

A procedure has been developed for uncertainty evaluation that draws on one or more of the following: (i) information uncovered in historical documents dating to the time when these materials were first produced, possibly including measurement results that are only summarized in the corresponding certificates; (ii) expert knowledge about the expected performance of analytical methods that were in use at the time when these materials were produced; and (iii) the Horwitz formula. The development was motivated by the need to update certificates of older NIST reference materials that are still available for sale, but were not originally qualified with uncertainty evaluations that conform to current requirements and state of the art.

For all historical measurands for which a Type A evaluation was practicable based on (i), a corresponding evaluation was also obtained by application of the conventional Horwitz formula: the results are depicted as open circles in Fig. 1. The equation of the (blue) straight line, of slope $<1$, fitted to them is what is dubbed the retuned Horwitz formula, because it is of the same functional form as Horwitz's original formula, but best matches the uncertainties associated with certified values in the subject certified reference materials produced at NIST.

The main purpose of this exercise was to apply the retuned Horwitz formula in cases where there is no information other than a mass fraction, for example those represented by red dots 
in Fig. 3. These cases obviously were not used for the tune-up. However, the retuned formula was applied also to cases where a Type A evaluation was possible, e.g., to SRM 2161, so a considered choice could be made of what appears to be the more trustworthy, or possibly more conservative, uncertainty evaluation, based on knowledge of the analytical methods involved. In the case of SRM 2161, $U_{\mathrm{HR}}$ turned out greater than $U_{\mathrm{S}}$ only for antimony, boron, niobium, and vanadium, among the 19 elements with certified mass fraction values.

When pairs of corresponding values of $U_{\mathrm{S}}(w)$ and $U_{\mathrm{H}}(w)$ are depicted in a scatterplot (Figure 1), the pattern that emerges indicates the logarithms of these quantities are approximately linearly related, but the slope of a best fitting line is appreciably $<1(0.5625$, in fact). The linearity shows that the relationship between expanded uncertainty and mass fraction of the analyte summarized in Horwitz's formula still prevails in a more restricted setting (selected NIST Standard Reference Materials), but $U(w)$ grows with $w$ at a lower rate than in the dataset Horwitz used originally to calibrate the relationship between $U(w)$ and $w$. The fact that the retuned relationship has slope $<1$ is not surprising considering the dataset Horwitz used comprised interlaboratory studies, while reference materials produced by NIST have relied on specially designed, interlaboratory, inter-method studies with carefully selected, expert participants and data subjected to thorough critical evaluation.

\section{Conclusions}

For older certified reference materials with certificates that do not fully comply with ISO Guide 31 and the GUM by, for example, having no uncertainty estimates, this paper demonstrates options for upgrading the Certificates of Analysis with uncertainty estimates. The best case is one in which the project records contain replicate values from multiple test methods for each measurand. In that case, one can apply a Bayesian approach to uncertainty estimation similar to the way modern consensus calculations are often performed. When the records lack replicate results for the contributions by each collaborator, the task of uncertainty estimation can be addressed using the six-step approach and retuned Horwitz relation, provided the user has the benefit of expert guidance about the capabilities of the analytical methods used in the project.

NIST analytical chemists and SRM project managers have long followed procedures that are believed to be in general compliance with current NIST practices for SRM certification and the NIST Quality System based on ISO 17025 [12] and ISO 17034 [13]. NIST has long used the approach of homogeneity testing of candidate materials and application of multiple quantitative test methods at NIST and at expert collaborating laboratories. Arguably, practices for uncertainty estimation have seen considerable development in recent years. However, some thought was given to uncertainty even in the early days. Descriptions of uncertainty slowly became more sophisticated over the decades, until by the 1970s, Certificates of Analysis contained what amounts to estimates that can be defined as combined standard uncertainties, often based on lab-to-lab reproducibility and expert judgement as estimators of the major uncertainty components.

Therefore, it is justified to reevaluate recorded data from older SRMs, even when the data are sparse. The discussions in this paper show how it is being done for selected metals, alloys, and geological materials SRMs produced 40 years to 60 years ago. Issuance of revised and 
modernized certificates of analysis is expected to make these SRMs remain viable for decades to come.

\section{References}

[1] ISO Guide 31:2015; Reference materials - Contents of certificates, labels and accompanying documentation; ISO/REMCO; https://www.iso.org/standard/52468.html, accessed May 2019

[2] JCGM 100:2008; Evaluation of Measurement Data - Guide to the Expression of Uncertainty in Measurement (GUM 1995 with Minor Corrections); Joint Committee for Guides in Metrology (JCGM). www.bipm.org/utils/common/documents/jcgm/JCGM_100_2008_E.pdf, accessed May 2019

[3] Horwitz W (2003) The certainty of uncertainty. J. AOAC Int.; 86(1); pp 109-111.

[4] AMC Tech. Brief 17, (2004); The amazing Horwitz function. Royal Soc. Chem; ed Thompson M, 2 pp.

[5] Thompson M (2007) Limitations of the application of the Horwitz Equation: A rebuttal. Trends Anal. Chem., 26(7); 659-661.

[6] Adcock RJ (1878) A problem in least squares. Analyst; Ann. Math., 5(2): 53-54. doi: $10.2307 / 2635758$

[7] Deming WE (1943) Statistical Adjustment of Data; Wiley, NY (Dover Publications edition, 1985); ISBN 0-486-64685-8.

[8] R Core Team (2018) R: A Language and Environment for Statistical Computing; R: A Language and Environment for Statistical Computing, Vienna, Austria. https://www.R-project.org/, accessed May 2019

[9] Manuilova A, Koiwanit J, Piewkhaow L, Wilson M, Chan CW, Tontiwachwuthikul P (2014) Life Cycle Assessment of Post-Combustion $\mathrm{CO}_{2}$ Capture and $\mathrm{CO}_{2}$-Enhanced Oil Recovery Based on the Boundary Dam Integrated Carbon Capture and Storage Demonstration Project; Energy Procedia; Vol. 63; pp 7398-7407.

[10] Geyer CJ and Johnson LT (2017) mcmc: Markov Chain Monte Carlo; R package version 0.9-5. https://CRAN.R-project.org/package=mcmc, accessed May 2019

[11] Bell RK (1965) Methods for the Chemical Analysis of NBS Copper-Base Spectrochemical Standards, NBS Misc. Publ. 260-7; U.S. Dept. Commerce, Washington DC; 99 pp. https://www.govinfo.gov/app/details/GOVPUB-C13$1 \mathrm{~d} 1 \mathrm{~d} 64 \mathrm{ad} 49 \mathrm{f} 9 \mathrm{bb} 7589 \mathrm{a} 5 \mathrm{fbd0dbb83280}$, accessed May 2019

[12] ISO/IEC 17025:2017; General requirements for the competence of testing and calibration laboratories; ISO; https://www.iso.org/standard/66912.html, accessed May 2019

[13] ISO 17034:2016; General requirements for the competence of reference material producers; ISO; https://www.iso.org/standard/29357.html, accessed May 2019 


\title{
Appendix
}

Unofficial copies of SRM Certificates referenced in the document are reproduced here. Official copies of the current versions are available for free download from www.nist $/ \mathrm{gov} / \mathrm{srm}$.

\section{Certificate of Analysis for SRM 158a Silicon Bronze (chip form)}

\author{
UNITED STATES DEPARTMENT OF COMMERCE \\ WASHINGTON 25, D.C.
}

\section{\$2ational 疎ureau of Standards Certificate of Analyses}

\section{Standard Sample 158 A \\ Silicon Bronze}

\begin{tabular}{|c|c|c|c|c|c|c|c|c|c|c|}
\hline 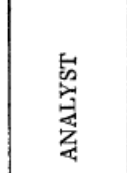 & 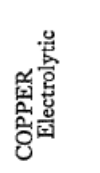 & $\begin{array}{l}\text { ㄱㅇㅇ } \\
\text { 先 } \\
\text { 是 }\end{array}$ & $\begin{array}{l}\text { O } \\
\text { N } \\
\text { Uñ } \\
\text { 总 }\end{array}$ & $\begin{array}{l}\text { Z } \\
\text { 吕 }\end{array}$ & 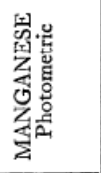 & 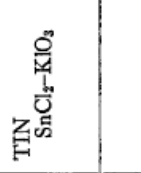 & 葛 & 愛 & 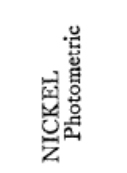 & 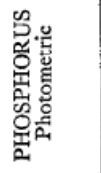 \\
\hline 1............... & a 90.94 & b 3.01 & 2.09 & - 1.24 & 1.11 & 0.96 & ${ }^{t} 0.46$ & $=0.093$ & h 0.0011 & ${ }^{i} 0.027$ \\
\hline 2 & j 90.87 & $\left.\begin{array}{l}k 3.00 \\
13.08\end{array}\right\}$ & $\mathrm{m} 2.01$ & - 1.18 & n 1.13 & $\circ .98$ & D. 48 & & & \\
\hline 3 & 490.95 & $=3.04$ & B 2.11 & - 1.25 & 口 1.11 & t. 96 & ". 44 & v. 10 & `. 0011 & w. 027 \\
\hline 4 & a 90.93 & $\left.\begin{array}{l}13.02 \\
\times 3.03\end{array}\right\}$ & 52.09 & $=1.23$ & n 1.11 & t. 96 & ะ1. 46 & จ. 10 & h. .0007 & $=.025$ \\
\hline 5 & 2290.95 & 233.00 & $\approx 42.08$ & ${ }^{25} 1.24$ & $x 61.10$ & ${ }^{27} .94$ & D. 45 & 28.096 & & \\
\hline Average.. & 90.93 & 3.03 & 2.08 & 1.23 & 1.11 & 0.96 & 0.46 & 0.097 & 0.001 & 0.026 \\
\hline \multicolumn{4}{|c|}{ 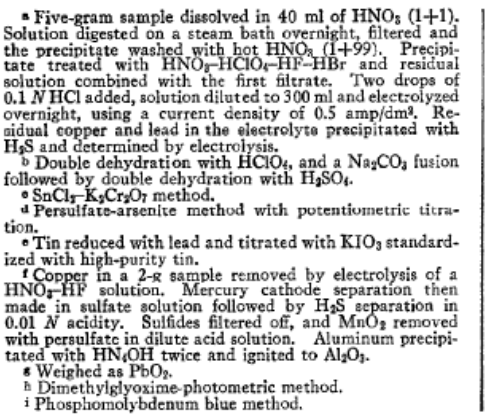 } & \multicolumn{3}{|c|}{ 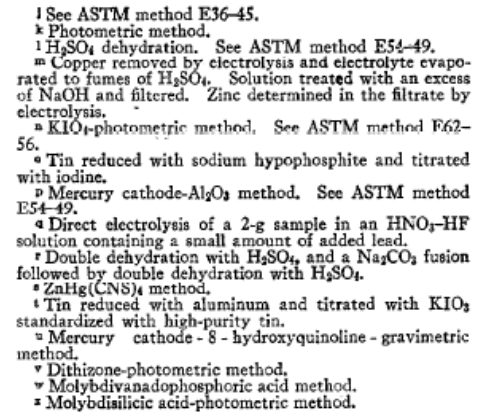 } & \multicolumn{4}{|c|}{ 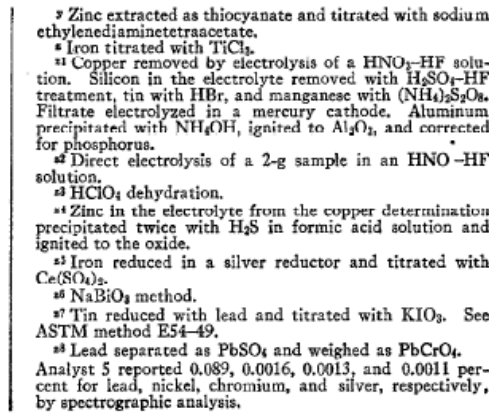 } \\
\hline
\end{tabular}

List of Analysts

1. Nonferrous Laboratory, National Bureau of Standards, R. K. Bell

in charge. Analysis by E. E. Maczkowske. 3. E. L. Smith, H. J. Smith, R. C. Burnham, and A. B. Feest, Chase
4. O. P. Case, G. A. Reihl, W. H. Taras, and Kathleen M. O'Brien, 5. K. H. Storks, E. Bloom, Jr., and E. K. Jaycox, Bell Telephone Laboratories, Murray Hill, N.J. 


\title{
2018 Certificate of Analysis for SRM 158a Silicon Bronze (chip form)
}

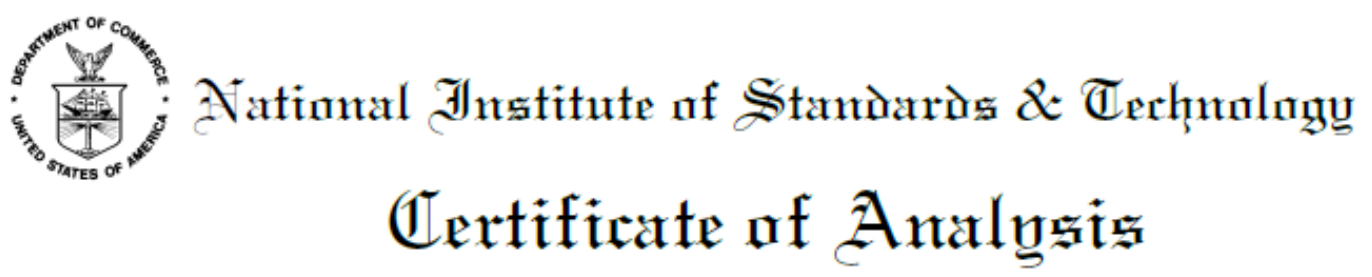

\author{
Standard Reference Material ${ }^{\circledR} 158 \mathrm{a}$
}

\author{
Silicon Bronze \\ (chip form)
}

\begin{abstract}
This Standard Reference Material (SRM) is intended primarily for use in validation of chemical and instrumental methods of analysis for element contents of bronze alloys and materials of similar matrix. It can be used to validate value assignment of a laboratory's in-house reference materials. A unit of SRM 158a consists of one bottle containing approximately $150 \mathrm{~g}$ of chips produced by a milling machine.
\end{abstract}

Certified Mass Fraction Values: Certified values for constituents of SRM 158a are reported in Table 1 as mass fractions of the elements in a bronze alloy matrix [1]. A NIST certified value is a value for which NIST has the highest confidence in its accuracy in that all known or suspected sources of bias have been taken into account [2]. A certified value is the present best estimate of the true value. The certified values are metrologically traceable to the SI derived unit of mass fraction (expressed as percent). The expanded uncertainty estimates are expressed at a confidence level of approximately $95 \%$, calculated following the ISO/JCGM Guide [3-10].

Table 1. Certified Mass Fraction Values for SRM 158a Silicon Bronze (chip form)

$\begin{array}{lcc}\text { Constituent } & \begin{array}{c}\text { Mass Fraction } \\ (\%)\end{array} & \begin{array}{c}\text { Expanded Unce } \\ (\%)\end{array} \\ \text { Aluminum (A1) } & 0.4580 & 0.0094 \\ \text { Copper }(\mathrm{Cu}) & 90.93 & 0.29 \\ \text { Iron }(\mathrm{Fe}) & 1.228 & 0.015 \\ \text { Lead }(\mathrm{Pb}) & 0.0973 & 0.0048 \\ \text { Manganese }(\mathrm{Mn}) & 1.112 & 0.014 \\ \text { Phosphorus }(\mathrm{P}) & 0.0263 & 0.0028 \\ \text { Silicon }(\mathrm{Si}) & 3.026 & 0.021 \\ \text { Tin }(\mathrm{Sn}) & 0.960 & 0.013 \\ \text { Zinc }(\mathrm{Zn}) & 2.076 & 0.019\end{array}$

Expiration of Certification: The certification of SRM 158a is valid indefinitely within the measurement uncertainty specified, provided the SRM is handled and stored in accordance with instructions given in this certificate (see "Instructions for Handling, Storage, and Use"). Periodic recertification of this SRM is not required. The certification is nullified if the SRM is damaged, contaminated, or otherwise modified.

Maintenance of SRM Certification: NIST will monitor this SRM over the period of its certification. If substantive technical changes occur that affect the certification before the expiration of this certificate, NIST will notify the purchaser. Registration (see attached sheet or register online) will facilitate notification.

Coordination of technical measurements for certification was performed by R.K. Bell, formerly of NIST. Review and revision of values and uncertainty estimates was coordinated by J.R. Sieber of the NIST Chemical Sciences Division.

Statistical consultation for this SRM was provided by A. Possolo of the NIST Statistical Engineering Division.

Carlos A. Gonzalez, Chief Chemical Sciences Division

Gaithersburg, MD 20899

Certificate Issue Date: 23 August 2018

Certificate Revision History on Last Page

SRM 158a
Steven J. Choquette, Director Office of Reference Materials

Page 1 of 4 
Support aspects involved in the issuance of this SRM were coordinated through the NIST Office of Reference Materials.

\section{INSTRUCTIONS FOR HANDLING, STORAGE, AND USE}

Silicon bronze chips may be analyzed in the as-received form. Test methods used to characterize the material used sample quantities of $2 \mathrm{~g}$ or more. While the material is believed to be homogeneous at lower quantities, it has not been tested in amounts $<2 \mathrm{~g}$. Before sampling, it is recommended to mix bottle contents by inverting and rotating the bottle by hand for at least one minute. A bottle containing unused material should be recapped immediately and stored at room temperature away from light.

To use the uncertainty estimates given in this certificate, divide the expanded uncertainty by a coverage factor of $k=2$ to obtain the combined standard uncertainty. The effective degrees of freedom of the combined standard uncertainty are $\geq 60$.

\section{PREPARATION AND ANALYSIS ${ }^{(1)}$}

The material was sieved, blended and bottled at NIST. Homogeneity testing of samples from the final lot was performed J.E. Cumbo, Airco Alloys (Niagara Falls, NY) and J.C. Cline, Interlake, Inc. (Beverly, OH). Analyses for certification were performed using the test methods listed in Table 2.

Analyses leading to the certification of this SRM were performed at NIST by R.K. Bell and E.E. Maczkowske, formerly of NIST. Analytical determinations were also performed by A.W. Young, Bridgeport Brass (Bridgeport, CT); E.L. Smith, H.J. Smith, R.C. Burnham, and A.B. Feest, Chase Brass and Copper Co. (Waterbury, CT); O.P. Case, G.A. Reihl, W.T. Taras, and K.M. O'Brien, The American Brass Co. (Waterbury, CT); and K.H. Storks, E. Bloom, Jr., and E.K. Jaycox, Bell Telephone Laboratories (Murray Hill, NJ).

Table 2. Test Methods Employed in the Certification of SRM 158a Silicon Bronze (chip form)

\begin{tabular}{|c|c|}
\hline Element & Test Methods Used at NIST and Collaborating Laboratories \\
\hline Aluminum & $\begin{array}{l}\text { - } \mathrm{Cu} \text { in a } 2 \mathrm{~g} \text { sample removed by electrolysis of a } \mathrm{HNO}_{3}-\mathrm{HF} \text { solution. Mercury cathode } \\
\text { separation then made in sulfate solution followed by } \mathrm{H}_{2} \mathrm{~S} \text { separation in } 0.01 \mathrm{~N} \text { acidity. } \\
\text { Sulfides filtered off, and } \mathrm{MnO}_{2} \text { removed with persulfate in dilute acid solution. Al } \\
\text { precipitated twice with } \mathrm{NH}_{4} \mathrm{OH} \text { and ignited to } \mathrm{Al}_{2} \mathrm{O}_{3} \text {.; } \\
\text { - Mercury cathode- } \mathrm{Al}_{2} \mathrm{O}_{3} \text { method (see ASTM International method E54-49); } \\
\text { - Mercury cathode } 8 \text {-hydroxyquinoline gravimetric method; } \\
\text { - } \mathrm{Cu} \text { removed by electrolysis of a } \mathrm{HNO}_{3}-\mathrm{HF} \text { solution. } \mathrm{Si} \text { in the electrolyte removed with } \\
\mathrm{H}_{2} \mathrm{SO}_{4}-\mathrm{HF} \text { treatment, } \mathrm{Sn} \text { with } \mathrm{HBr} \text {, and } \mathrm{Mn} \text { with }\left(\mathrm{NH}_{4}\right)_{2} \mathrm{~S}_{2} \mathrm{O}_{8} \text {. Filtrate electrolyzed in a } \\
\text { mercury cathode. } \mathrm{Al} \text { precipitated with } \mathrm{NH}_{4} \mathrm{OH} \text {, ignited to } \mathrm{Al}_{2} \mathrm{O}_{3} \text {, and corrected for } \mathrm{P} \text {. }\end{array}$ \\
\hline Copper & $\begin{array}{l}\text { - } 5.0 \mathrm{~g} \text { sample dissolved in } 40 \mathrm{~mL} \mathrm{HNO}_{3}(1+1) \text {. Solution digested on steam bath overnight, } \\
\text { filtered and the precipitate washed with hot } \mathrm{HNO}_{3}(1+99) \text {. Precipitate treated with } \\
\mathrm{HNO}_{3}-\mathrm{HClO}_{4}-\mathrm{HF}-\mathrm{HBr} \text { and residual solution combined with first filtrate. Two drops } \\
0.1 \mathrm{NHCl} \text { added, solution diluted to } 300 \mathrm{~mL} \text { and electrolyzed overnight, using a current } \\
\text { density of } 0.5 \mathrm{~A} / \mathrm{dm}^{2} \text {. Residual } \mathrm{Cu} \text { and } \mathrm{Pb} \text { in electrolyte precipitated with } \mathrm{H}_{2} \mathrm{~S} \text { and } \\
\text { determined by electrolysis.; } \\
\text { - ASTM International method E36-45; } \\
\text { - Direct electrolysis of a } 2 \mathrm{~g} \text { sample in } \mathrm{HNO}_{3}-\mathrm{HF} \text { solution containing small amount of added } \\
\mathrm{Pb} \text {; } \\
\text { - Direct electrolysis of a } 2 \mathrm{~g} \text { sample in } \mathrm{HNO}_{3}-\mathrm{HF} \text { solution. }\end{array}$ \\
\hline Iron & $\begin{array}{l}\text { - } \mathrm{SnCl}_{2}-\mathrm{K}_{2} \mathrm{Cr}_{2} \mathrm{O}_{7} \text { method; } \\
\text { - } \mathrm{Fe} \text { titrated with } \mathrm{TiCl} \\
\text { - } \mathrm{Fe} \text { reduced in a silver redactor and titrated with } \mathrm{Ce}\left(\mathrm{SO}_{4}\right)_{2}\end{array}$ \\
\hline Lead & $\begin{array}{l}\text { - Weighed as } \mathrm{PbO}_{2} \\
\text { - Dithizone-photometric method; } \\
\text { - } \mathrm{Pb} \text { separated as } \mathrm{PbSO}_{4} \text { and weighed as } \mathrm{PbCrO}_{4}\end{array}$ \\
\hline
\end{tabular}

(1) Certain commercial equipment, instruments or materials are identified in this certificate to adequately specify the experimental procedure. Such identification does not imply recommendation or endorsement by the National Institute of Standards and Technology, nor does it imply that the materials or equipment identified are necessarily the best available for the purpose. SRM 158a

Page 2 of 4 
Table 2. Test Methods Employed in the Certification of SRM 158a Silicon Bronze (chip form)

\begin{tabular}{|c|c|}
\hline Element & Test Methods Used at NIST and Collaborating Laboratories \\
\hline Manganese & $\begin{array}{l}\text { - Persulfate-arsenite method with potentiometric titration; } \\
\text { - } \mathrm{KIO}_{4} \text { photometric method (see ASTM International method E62-56); } \\
\text { - } \mathrm{NaBiO}_{3} \text { method. }\end{array}$ \\
\hline Phosphorus & $\begin{array}{l}\text { - Phosphomolybdenum blue method; } \\
\text { - Molybdivanadophosphoric acid method. }\end{array}$ \\
\hline Silicon & $\begin{array}{l}\text { - Double dehydration with } \mathrm{HClO}_{4} \text {, and a } \mathrm{Na}_{2} \mathrm{CO}_{3} \text { fusion followed by double dehydration with } \\
\mathrm{H}_{2} \mathrm{SO}_{4} \text {; } \\
\text { - Photometric method; } \\
\text { - } \mathrm{H}_{2} \mathrm{SO}_{4} \text { dehydration (see } \mathrm{ASTM}_{\text {International method } \mathrm{E} 54-49 \text { ); }} \\
\text { - Double dehydration with } \mathrm{H}_{2} \mathrm{SO}_{4} \text {, and a } \mathrm{Na}_{2} \mathrm{CO}_{3} \text { fusion followed by double dehydration with } \\
\mathrm{H}_{2} \mathrm{SO}_{4} \text {; } \\
\text { - } \mathrm{Molybdisilicic} \mathrm{acid-photometric} \mathrm{method;}_{\text {- }} \mathrm{HClO}_{4} \text { dehydration. }\end{array}$ \\
\hline Tin & $\begin{array}{l}\text { - Sn reduced with } \mathrm{Pb} \text { and titrated with } \mathrm{KIO}_{3} \text { standardized with high-purity } \mathrm{Sn} \text {; } \\
\text { - } \mathrm{Sn} \text { reduced with sodium hypophosphite and titrated with iodine; } \\
\text { - Sn reduced with } \mathrm{Al} \text { and titrated with } \mathrm{KIO}_{3} \text { standardized with high-purity Sn; } \\
\text { - } \mathrm{Sn} \text { reduced with } \mathrm{Pb} \text { and titrated with } \mathrm{KIO} \text { (see ASTM International method 54-49). }\end{array}$ \\
\hline Zine & $\begin{array}{l}\text { - } \mathrm{Cu} \text { removed by electrolysis and electrolyte evaporated to fumes of } \mathrm{H}_{2} \mathrm{SO}_{4} \text {. Solution treated } \\
\text { with an excess of } \mathrm{NaOH} \text { and filtered. } \mathrm{Zn} \text { determined in filtrate by electrolysis.; } \\
\text { - } \mathrm{ZnHg}(\mathrm{CNS})_{4} \text { method; } \\
\text { - } \mathrm{Zn} \text { extracted as thiocyanate and titrated with sodium ethylenediaminetetraacetate; } \\
\text { - } \mathrm{Zn} \text { in the electrolyte from the } \mathrm{Cu} \text { determination precipitated twice with } \mathrm{H}_{2} \mathrm{~S} \text { in formic acid } \\
\text { solution and ignited to } \mathrm{ZnO} \text {. }\end{array}$ \\
\hline
\end{tabular}

ADDITIONAL CONSTITUENTS: Noncertified values are provided for the following additional constituents in SRM 158a.

Information Mass Fraction Values: Information values for constituents in SRM 158a are reported as mass fractions in Table 3. An information value is a value that may be of interest to the SRM user, but insufficient information is available to assess the uncertainty associated with the value [2]. Information values cannot be used to establish metrological traceability.

Table 3. Information Mass Fraction Values for SRM 158a Silicon Bronze (chip form)

$\begin{array}{lc}\text { Constituent } & \begin{array}{c}\text { Mass Fraction } \\ (\%)\end{array} \\ \text { Chromium }(\mathrm{Cr}) & 0.001 \\ \text { Nickel }(\mathrm{Ni}) & 0.001 \\ \text { Silver }(\mathrm{Ag}) & 0.001\end{array}$

\section{NOTICE TO USERS}

NIST strives to maintain the SRM inventory supply, but NIST cannot guarantee the continued or continuous supply of any specific SRM. Accordingly, NIST encourages the use of this SRM as a primary benchmark for the quality and accuracy of the user's in-house reference materials and working standards. As such, the SRM should be used to validate the more routinely used reference materials in a laboratory. Comparisons between the SRM and a laboratory's in-house reference materials or working measurement standards should take place at intervals appropriate to the conservation of the SRM and the stability of relevant in-house materials. For further guidance on how this approach can be implemented, contact NIST by email at srms@nist.gov. 


\section{REFERENCES}

[1] Thompson, A.; Taylor, B.N.; Guide for the Use of the International System of Units (SI); NIST Special Publication 811; U.S. Government Printing Office: Washington, DC (2008); available at https://www.nist.gov/pml/pubs/sp811/index.cfm (accessed Aug 2018).

[2] May, W.; Parris, R.; Beck II, C.; Fassett, J.; Greenberg, R.; Guenther, F.; Kramer, G.; Wise, S.; Gills, T.; Colbert, J.; Gettings, R.; MacDonald, B.; Definition of Terms and Modes Used at NIST for Value-Assignment of Reference Materials for Chemical Measurements; NIST Special Publication 260-136 U.S. Government Printing Office: Washington, DC (2000); available at https:/www.nist.gov/srm/upload/SP260-136.PDF (accessed Aug 2018).

[3] Adcock, R.J.; A Problem in Least Squares; The Analyst, Vol. 5, pp. :53-54 (1878).

[4] Deming, W.E.; Statistical Adjustment of Data; John Wiley \& Sons, New York, NY (1943).

[5] Horwitz, W., The certainty of uncertainty. J. AOAC International, Vol. 86, Issue 1, pp. 109-111, (2003).

[6] Manuilova, E.; Schuetzenmeister, A.; Model, F.; mor: Method Comparison Regression, (2014). https://CRAN.R-project.org/package=mer R package version 1.2.1 (accessed July 2018).

[7] R Core Team, R: A Language and Environment for Statistical Computing. R Foundation for Statistical Computing, Vienna, Austria, 2015. https://www.R-project.org/ (accessed July 2018).

[8] Thompson, M.; The amazing Horwitz function; AMC Technical Brief 17, Royal Society of Chemistry, November 2004.

[9] Thompson, M.; Limitations of the Application of the Horwitz Equation: A Rebuttal. Trends in Analytical Chemistry, Vol. 26, Issue 7, pp. 659-661 (2007).

[10] JCGM 100:2008; Evaluation of Measurement Data - Guide to the Expression of Uncertainty in Measurement; (ISO GUM 1995 with Minor Corrections), Joint Committee for Guides in Metrology (JCGM) (2008); available at https://www.bipm.org/utils/common/documents/jcgm/JCGM_100_2008_E.pdf (accessed Aug 2018); see also Taylor, B.N.; Kuyatt, C.E.; Guidelines for Evaluating and Expressing the Uncertainty of NIST Measurement Results; NIST Technical Note 1297, U.S. Government Printing Office: Washington, DC (1994); available at https://www.nist.gov/pml/nist-technical-note-1297 (accessed Aug 2018).

Certificate Revision History: 23 August 2018 (Revised values and uncertainties for certified constituents; update of the certificate to current NIST standards; editorial changes); 8 August 1961 (Original certificate date).

Users of this SRM should ensure that the Certificate of Analysis in their possession is current. This can be accomplished by contacting the SRM Program: telephone (301) 975-2200; fax (301) 948-3730; e-mailsrminfo@nist.gov; or via the Internet at https://www.nist.gov/srm. 


\title{
2018 Certificate of Analysis for SRM 2161 Low Alloy Steel (chip form)
}

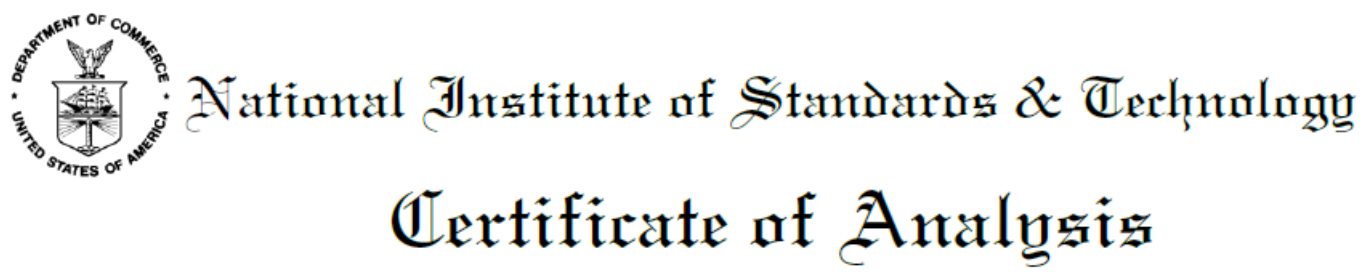

\author{
Standard Reference Material ${ }^{\circledR} 2161$ \\ Low Alloy Steel \\ (chip form)
}

\begin{abstract}
This Standard Reference Material (SRM) is a low alloy steel intended primarily for evaluation of methods for analysis of elements in low alloy steel and materials of a similar matrix. It can be used to validate value assignment of in-house reference materials. A unit of SRM 2161 consists of one bottle containing approximately $150 \mathrm{~g}$ of chips.

Certified Mass Fraction Values: Certified values for constituents in SRM 2161 are listed in Table 1 as mass fractions of the total amounts of the elements in a steel matrix [1]. A NIST certified value is a value for which NIST has the highest confidence in its accuracy in that all known or suspected sources of bias have been taken into account [2]. A certified value is the present best estimate of the true value. The certified values are metrologically traceable to the SI derived unit of mass fraction expressed as percent. The expanded uncertainty estimates are expressed at a coverage level of approximately $95 \%$, using a coverage factor $k=2.00[3-5]$
\end{abstract}

Table 1. Certified Mass Fraction Values in SRM 2161 Low Alloy Steel

Constituent

Aluminum (Al)

Antimony $(\mathrm{Sb})$

Arsenic (As)

Boron (B)

Cobalt (Co)

Chromium (Cr)

Copper $(\mathrm{Cu})$

Manganese (Mn)

Molybdenum (Mo)

Niobium (Nb)

Nickel (Ni)

Phosphorus (P)

Silicon $(\mathrm{Si})$

Sulfur (S)

Tin (Sn)

Tantalum $(\mathrm{Ta})$

Titanium ( $\mathrm{Ti}$ )

Vanadium (V)

Zirconium (Zr)
Mass Fraction

(\%)

0.0539

0.00548

0.0131

0.00215

0.0256

0.2195

0.2973

0.680

0.1030

0.01978

1.999

0.0407

0.1816

0.0347

0.0474

0.0522

0.180

0.0540

0.0132
Expanded Uncertainty

(\%)

\subsection{8}

0.00022

0.0022

0.00012

0.0036

0.0032

0.0031

0.014

0.0031

0.00055

0.053

0.0014

0.0088

0.0030

0.0027

0.0012

0.013

0.0010

0.0025

Expiration of Certification: The certification of SRM 2161 is valid indefinitely, within the measurement uncertainties specified, provided the SRM is handled and stored in accordance with the instructions given in this certificate (see "Instructions for Storage, Handling and Use"). Reference values are expected also to remain valid indefinitely. Periodic recalibration or recertification of this SRM is not required. The certification is nullified if the SRM is damaged, contaminated, or otherwise modified.

Gaithersburg, MD 20899

Certificate Issue Date: 22 March 2018

SRM 2161
Carlos A. Gonzalez, Chief Chemical Sciences Division

Steven J. Choquette, Director Office of Reference Materials

Page 1 of 4 
Maintenance of SRM Certification: NIST will monitor this material over the period of its certification. If substantive technical changes occur that affect the certification before the expiration of this certificate, NIST will notify the purchaser. Registration (see attached sheet or register online) will facilitate notification.

Coordination of technical measurements for the certification of this SRM was performed by J.R. Sieber of the NIST Chemical Sciences Division. Statistical consultation for this SRM was provided by J.H. Yen of the NIST Statistical Engineering Division.

Measurements for value assignment of SRM 2161 were performed by A.F. Marlow, S.A. Rabb and J.R. Sieber of the NIST Chemical Sciences Division. Additional analyses were performed by collaborating laboratories, including C. McNeish, B. McNichols, A. Scrimshaw, and S. Truman of ArcelorMittal Dofasco, Mechanical and Chemical Test Laboratory (Hamilton, ON, Canada), and A. Phillips, R. Crouthamel, S. Stone, A. Deveau, and L. Dilks of Laboratory Testing, Inc. (Hatfield, PA).

Support aspects involved in the issuance of this SRM were coordinated through the NIST Office of Reference Materials.

\section{INSTRUCTIONS FOR STORAGE, HANDLING AND USE}

To relate analytical determinations to the certified values in this Certificate of Analysis, a minimum sample quantity of $200 \mathrm{mg}$ is recommended. Specimens may be used directly from the bottle without pre-treatment. The material should be stored in its tightly sealed, original bottle in a cool, dry location.

\section{PREPARATION AND ANALYSIS ${ }^{(1)}$}

The material for SRM 2161 was vacuum induction melted at Carpenter Technology Corp. (Reading, PA) and supplied in the form of rods. The material was chipped and packaged at NIST in the Office of Reference Materials. Homogeneity testing was performed at NIST using X-ray fluorescence spectrometry.

ADDITIONAL CONSTITUENTS: Noncertified values are provided for the following additional constituents in SRM 2161.

Reference Mass Fraction Values: Reference values for constituents of SRM 2161 are reported in Table 2 as mass fractions of the total element in a steel matrix. A reference value is a non-certified value that is the present best estimate of the true value based on available data; however, the value does not meet the NIST criteria for certification and is provided with an associated uncertainty that may reflect only measurement precision, may not include all sources of uncertainty, or may reflect a lack of sufficient statistical agreement among multiple analytical methods [2]. The reference values as determined by the methods used, are metrologically traceable to the derived SI unit for mass fraction expressed as percent. The reference values are the equally weighted means of results obtained using the test methods in Table 4. The expanded uncertainty, $U$, is calculated as $U=k u_{\mathrm{c}}$ where $u_{\mathrm{c}}$ is the combined standard uncertainty of the reported value and $k=2.00$ is the coverage factor for an approximate confidence level of $95 \%$ [3-5]. The value of $u_{\mathrm{c}}$ incorporates contributions to the uncertainty from random measurement variability, potential systematic differences between laboratories and analytical methods, and possible material heterogeneity.

Table 2. Reference Mass Fraction Values for SRM 2161 Low Alloy Steel

$\begin{array}{lcc}\text { Constituent } & \begin{array}{c}\text { Mass Fraction } \\ (\%)\end{array} & \begin{array}{c}\text { Expanded Uncertainty } \\ (\%)\end{array} \\ \text { Carbon }(\mathrm{C}) & 1.02 & 0.03 \\ \text { Nitrogen }(\mathrm{N}) & 0.0049 & 0.0003\end{array}$

(1) Certain commercial equipment, instruments, or materials are identified in this certificate to adequately specify the experimental procedure. Such identification does not imply recommendation or endorsement by the National Institute of Standards and Technology, nor does it imply that the materials or equipment identified are necessarily the best available for the purpose. SRM 2161

Page 2 of 4 
Information Mass Fraction Values: Information values for constituents are reported in Table 3 as mass fractions of the total elements in a steel matrix. The values reported are estimates based on technical evaluation of the results reported from one or more test methods. An information value is a value that may be of interest to the SRM user, but insufficient information is available to assess the uncertainty associated with the value. Information values cannot be used to establish metrological traceability.

Table 3. Information Mass Fraction Values for SRM 2161 Low Alloy Steel

$\begin{array}{lc}\text { Constituent } & \begin{array}{c}\text { Mass Fraction } \\ (\mathrm{mg} / \mathrm{kg})\end{array} \\ \text { Bismuth (Bi) } & 0.2 \\ \text { Calcium (Ca) } & <1 \\ \text { Cerium (Ce) } & 3 \\ \text { Hydrogen (H) } & 2 \\ \text { Magnesium (Mg) } & <1 \\ \text { Oxygen (O) } & 150 \\ \text { Lead (Pb) } & 0.1 \\ \text { Selenium (Se) } & 2 \\ \text { Tellurium (Te) } & 2 \\ \text { Tungsten (W) } & <50 \\ & \\ & \\ \text { Iron (Fe) } & 95.0\end{array}$

Table 4. Test Methods for SRM 2161 Low Alloy Steel

Method

Arc-spark optical emission spectrometry:

Combustion with infrared detection:

Inductively coupled plasma optical emission spectrometry:

Inductively coupled plasma mass spectrometry:

Inert gas fusion with infrared or thermal conductivity detection:

$\mathrm{X}$-ray fluorescence spectrometry:
Constituents Determined

B, C, N, Al, Si, P, S, Ca, Ti, V, Cr, Mn, Co, $\mathrm{Ni}, \mathrm{Cu}, \mathrm{As}, \mathrm{Zr}, \mathrm{Nb}, \mathrm{Mo}, \mathrm{Sn}, \mathrm{Sb}, \mathrm{W}, \mathrm{Pb}$

C, S

B, Mg, Al, Si, P, Ca, Ti, V, Cr, Mn, Co, Ni, $\mathrm{Cu}, \mathrm{As}, \mathrm{Zr}, \mathrm{Nb}, \mathrm{Mo}, \mathrm{Sn}, \mathrm{Ce}, \mathrm{Ta}, \mathrm{W}$

$\mathrm{Se}, \mathrm{Sb}, \mathrm{Te}, \mathrm{Pb}, \mathrm{Bi}$

$\mathrm{H}, \mathrm{N}, \mathrm{O}$

B, C, Al, Si, P, S, Ti, V, Cr, Mn, Fe, Co, Ni, $\mathrm{Cu}, \mathrm{As}, \mathrm{Zr}, \mathrm{Nb}, \mathrm{Mo}, \mathrm{Sn}, \mathrm{Sb}, \mathrm{Ta}, \mathrm{W}$

\section{NOTICE TO USERS}

NIST strives to maintain the SRM inventory supply, but NIST cannot guarantee the continued or continuous supply of any specific SRM. Accordingly, NIST encourages the use of this SRM as a primary benchmark for the quality and accuracy of the user's in-house reference materials and working standards. As such, the SRM should be used to validate the more routinely used reference materials in a laboratory. Comparisons between the SRM and in-house reference materials or working measurement standards should take place at intervals appropriate to the conservation of the SRM and the stability of relevant in-house materials. For further guidance on how this approach can be implemented, contact NIST by email at srms@nist.gov. 


\section{REFERENCES}

[1] Thompson, A.; Taylor, B.N.; Guide for the Use of the International System of Units (SI); NIST Special Publication 811; U.S. Government Printing Office: Washington, DC (2008); available at https://www.nist.gov/pml/special-publication-811 (accessed Mar 2018).

[2] May, W.; Parris, R.; Beck, C.; Fassett, J.; Greenberg, R.; Guenther, F.; Kramer, G.; Wise, S.; Gills, T.; Colbert, J.; Gettings, R.; MacDonald, B.; Definitions of Terms and Modes Used at NIST for Value-Assignment of Reference Materials for Chemical Measurements; NIST Special Publication 260-136, U.S. Government Printing Office: Gaithersburg, MD (2000); available at https:/www.nist.gov/sites/default/files/documents/srm/SP260-136.PDF (accessed Mar 2018).

[3] JCGM 100:2008; Evaluation of Measurement Data - Guide to the Expression of Uncertainty in Measurement (GUM 1995 with Minor Corrections); Joint Committee for Guides in Metrology (2008); available at https://www.bipm.org/utils/common/documents/jcgm/JCGM_100_2008_E.pdf (accessed Mar 2018); see also Taylor, B.N.; Kuyatt, C.E.; Guidelines for Evaluating and Expressing the Uncertainty of NIST Measurement Results; NIST Technical Note 1297; U.S. Government Printing Office: Washington, DC (1994); available at https://www.nist.gov/pml/pubs/tn1297/index.cfm (accessed Mar 2018).

[4] JCGM 101:2008; Evaluation of Measurement Data - Supplement 1 to the "Guide to the Expression of Uncertainty in Measurement" - Propagation of Distributions Using a Monte Carlo Method; JCGM (2008); available at https://www.bipm.org/utils/common/documents/jcgm/JCGM_101_2008_E.pdf (accessed Mar 2018).

[5] Efron, B.; Tibshirani, R. J.; An Introduction to the Bootstrap, Chapman \& Hall, UK (1993).

Users of this SRM should ensure that the Certificate of Analysis in their possession is current. This can be accomplished by contacting the SRM Program: telephone (301)975-2200; fax (301) 948-3730; e-mailsrminfo@nist.gov; or via the Internet at https://www.nist.gov/srm. 